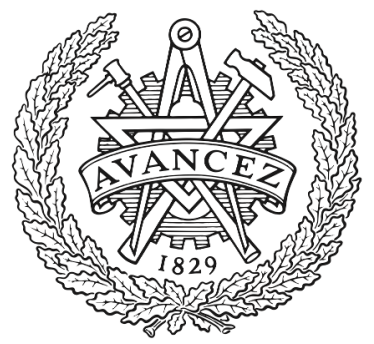

CHALMERS

UNIVERSITY OF TECHNOLOGY

\title{
Highly Concentrated Electrolytes: Electrochemical and Physicochemical Characteristics of LiPF6 in Propylene Carbonate Solutions
}

Downloaded from: https://research.chalmers.se, 2023-04-26 11:00 UTC

Citation for the original published paper (version of record):

Åvall, G., Wallenstein, J., Cheng, G. et al (2021). Highly Concentrated Electrolytes: Electrochemical and Physicochemical Characteristics of LiPF6

in Propylene Carbonate Solutions. Journal of the Electrochemical Society, 168(5).

http://dx.doi.org/10.1149/1945-7111/abfdc3

N.B. When citing this work, cite the original published paper. 
OPEN ACCESS

Highly Concentrated Electrolytes: Electrochemical and Physicochemical Characteristics of $\mathrm{LiPF}_{6}$ in Propylene Carbonate Solutions

To cite this article: Gustav Åvall et al 2021 J. Electrochem. Soc. 168050521

View the article online for updates and enhancements.

\section{0th ECS Meeting}

Oct 10-14, 2021, Orlando, Florida

Register early and save up to $20 \%$ on registration costs

Early registration deadline Sep 13

REGISTER NOW

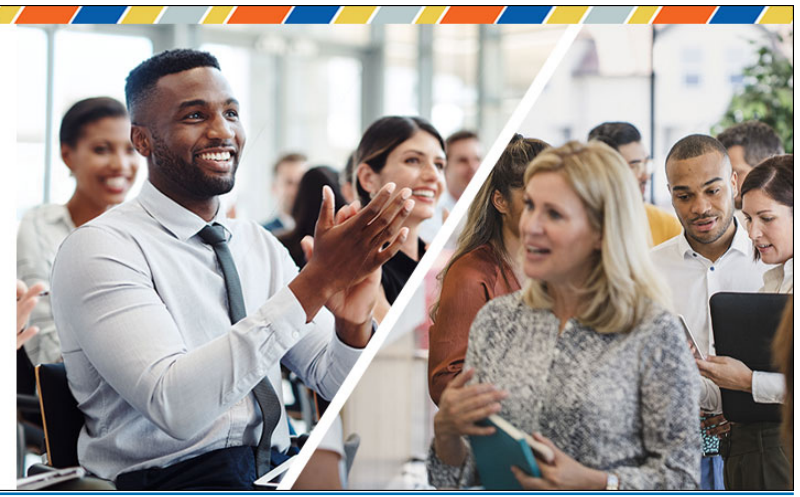




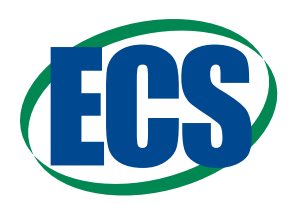

\title{
Highly Concentrated Electrolytes: Electrochemical and Physicochemical Characteristics of $\mathrm{LiPF}_{6}$ in Propylene Carbonate Solutions
}

\author{
Gustav Åvall, ${ }^{1}$ (i) Joachim Wallenstein, ${ }^{1}$ Gang Cheng, ${ }^{2,3}$ Kevin L. Gering, ${ }^{4, *}$ (i) \\ Patrik Johansson, ${ }^{1,5}(\mathbb{1})$ and Daniel P. Abraham ${ }^{2, *, z}$ (i) \\ ${ }^{1}$ Department of Physics, Chalmers University of Technology, 412 96, Gothenburg, Sweden \\ ${ }^{2}$ Chemical Sciences and Engineering, Argonne National Laboratory, Lemont, Illnois 60439, United States of America \\ ${ }^{3}$ Wildcat Discovery Technologies, San Diego, California 92121, United States of America \\ ${ }^{4}$ Idaho National Laboratory, Idaho Falls, Idaho 83415, United States of America \\ ${ }^{5}$ ALISTORE-European Research Institute, CNRS FR 3104, Hub de I'Energie, Rue Baudelocque, 80039 Amiens, France
}

\begin{abstract}
Highly concentrated electrolytes (HCEs) based on $\mathrm{LiPF}_{6}$ in propylene carbonate (PC) have been examined as lithium-ion battery electrolytes. These HCEs have lower ionic conductivities and higher viscosities than ethylene carbonate (EC) electrolytes with $1.2 \mathrm{M}$ $\mathrm{LiPF}_{6}$, but they have higher $\mathrm{Li}^{+}$ion transference numbers. Electrochemical cycling behaviour of $\mathrm{LiNi}_{0.8} \mathrm{Co}_{0.015} \mathrm{Al}_{0.05} \mathrm{O}_{2} / / \mathrm{graphite}$ cells with 3.2 $\mathrm{M} \mathrm{LiPF}_{6}$ in $\mathrm{PC}$ resembles that of cells with EC-based electrolytes; the HCE cells have higher impedance, which can be lowered by increasing test temperature. By employing Raman and infrared spectroscopy, combined with density functional theory and ab initio molecular dynamics simulations, we reveal that the $\mathrm{Li}^{+}$solvation structure and speciation are key factors that determine cell performance. Two distinct regimes are observed as a function of salt concentration-in the conventional regime, the solvation number (SN) is mostly constant, while in the HCE regime it decreases linearly. Graphite exfoliation is suppressed only at very high salt concentrations $(>2.4 \mathrm{M})$, where $[P C]_{\text {free }} /\left[\mathrm{Li}^{+}\right]<1$ and $\left[P F_{6}^{-}\right]_{\text {free }}>[P C]_{\text {free }}$. Results from the Advanced Electrolyte Model indicate that $\mathrm{Li}^{+}$desolvation improves at higher $\mathrm{LiPF}_{6} \mathrm{Concentrations}$, thereby mitigating PC co-intercalation into the graphite. However, $\mathrm{Li}^{+}$ion transport is hindered in the HCEs, which increases impedance at both the oxide-positive and graphite-negative electrodes.

(C) 2021 The Author(s). Published on behalf of The Electrochemical Society by IOP Publishing Limited. This is an open access article distributed under the terms of the Creative Commons Attribution 4.0 License (CC BY, http://creativecommons.org/licenses/ by/4.0/), which permits unrestricted reuse of the work in any medium, provided the original work is properly cited. [DOI: 10.1149/ 1945-7111/abfdc3]
\end{abstract}

Manuscript submitted March 4, 2021; revised manuscript received April 12, 2021. Published May 13, 2021.

Supplementary material for this article is available online

Commercial lithium-ion battery (LIB) electrolytes often consist of lithium hexafluorophosphate $\left(\mathrm{LiPF}_{6}\right)$ dissolved in mixtures of cyclic and linear carbonates. Among the former carbonates, propylene carbonate (PC) was one of the first solvents studied for both lithium metal batteries and LIBs, because of its high dielectric constant and excellent liquid range. ${ }^{1}$ It was soon discovered that pure PC based electrolytes caused irreversible capacity losses in cells with graphite anodes: PC has a tendency to co-intercalate with the cation, ultimately causing exfoliation and degradation of the graphite. ${ }^{1-6}$ Instead, ethylene carbonate (EC), which does not display these shortcomings and forms a stable SEI, became the LIB solvent of choice. Because EC is a solid at room temperature, it is often mixed with other solvents to decrease viscosity and extend the liquidus range of the electrolyte. These solvents are typically the linear carbonates; dimethyl carbonate (DMC), diethyl carbonate (DEC), dimethoxyethane (DME), and ethyl methyl carbonate (EMC).

In recent years, interest has increased in highly concentrated electrolytes (HCEs), which display features such as wide electrochemical stability windows (ESWs), reduced volatility, and increased liquidus range. $^{7-9}$ It has been shown that elevated salt concentrations suppress the exfoliation of graphite in pure PC based electrolytes: ${ }^{10-12}$ the reasons for this behaviour are not entirely clear. The beneficial properties of HCEs are believed to be directly or indirectly related to electrolyte speciation, which transforms from being rich in free solvent and with well-separated ions to more extensive ion-pairing and less free solvent, and finally to ionic networks with little or no free solvent. ${ }^{7}$

Proper understanding of the local structure around $\mathrm{Li}^{+}$, especially its first solvation shell is needed to explain the performance of LIB cells. There are conflicting reports on the $\mathrm{Li}^{+}$coordination number $(\mathrm{CN})$, i.e., the number of atomic species/ligands in the first

*Electrochemical Society Member.

${ }^{\mathrm{z}}$ E-mail: abraham@anl.gov solvation shell, in carbonate-based electrolytes, especially for those using PC as a solvent (Table I). CN is often used interchangeably with solvation number ( $\mathrm{SN}$ ), although the latter generally denotes molecular solvating species and includes the complete stable population of solvators within all solvation shells that accompany an ion. For low salt concentrations the $\mathrm{Li}^{+} \mathrm{CNs}$ vary between $1-5$ depending on the method and anion employed. ${ }^{11-24}$ Allen et al. report Raman-determined first solvation shell solvation numbers to be implausibly low in PC electrolytes and indicate that the difficulty of obtaining proper $\mathrm{CNs}$ in $\mathrm{PC}$ is due to its chirality, which affects the Raman peaks of the $\mathrm{Li}^{+}$coordinated PC. ${ }^{22}$ Note that for a solvent like PC, which can act as a bidentate ligand, the changes in the $\mathrm{CN}$ and $\mathrm{SN}$, respectively, may differ depending on the solvation structure (and to some extent also on the method applied to assess them). Barthel et al. found CNs as low as $1.7-2.3$ for $\mathrm{LiClO}_{4}$ in $\mathrm{PC},{ }^{13}$ while Brooksby and Fawcett report ion-pair formation at low $\mathrm{LiClO}_{4}$ concentrations and a CN of $3 .{ }^{15}$ Other studies found a $\mathrm{CN}$ between 2-4 for $\mathrm{LiClO}_{4}$ in $\mathrm{PC}{ }^{16-18}$ Two Raman studies on $0-3 \mathrm{M}$ $\mathrm{LiBF}_{4}$ in $\mathrm{PC}$ found CNs of $1.2-1.6,{ }^{19}$ and $4.0-1.5,{ }^{20}$ respectively. When $\mathrm{LiPF}_{6}$ is used as salt, the $\mathrm{CN}$ is frequently reported to be in the 4-5 range. ${ }^{12,14,20}$ Hwang et al. indicate that electrolytes based on $\mathrm{LiPF}_{6}$, when compared with $\mathrm{LiBF}_{4}$, have much lower fractions of contact ion-pairs (CIPs). ${ }^{20}$ This observation could imply that there is a substantial amount of PC in the first solvation shell of $\mathrm{Li}^{+}$even beyond the conventional $1 \mathrm{M}$ salt concentration, which has also been reported from classical molecular dynamics (MD) studies. ${ }^{25,26} \mathrm{By}$ studying the carbonyl peak of PC, Chapman et al. noted that the solvation number decreases from 4.5 to 2.0 as a function of salt concentration: similar observations were made for PC-DMC binary mixtures by Seo et al., who found that the number of PC molecules in the solvation shell drops from 3 to 1 as a function of salt concentration. ${ }^{23,24}$ While the research focus is typically on $\mathrm{Li}^{+}$ion $\mathrm{CN}$ and $\mathrm{SN}$, knowledge of anion solvation is also important. For typical organic battery electrolytes, the magnitude of anion solvation is much less than that for the cation; however, the former is not 
Table I. Lithium-ion CNs in carbonate-based electrolytes; * given as salt to solvent ratios.

\begin{tabular}{|c|c|c|c|c|c|}
\hline Salt & Solvent & {$\left[\mathrm{Li}^{+}\right] \mathrm{M}$} & $\mathrm{CN}$ & Method & References \\
\hline & & $0.12-1.29$ & $2.3-1.7$ & FTIR & 13 \\
\hline \multirow[t]{4}{*}{$\mathrm{LiClO}_{4}$} & $\mathrm{PC}$ & $0-1.7$ & 3.0 & ATR-IR, DFT & 15 \\
\hline & & $10^{-3}$ & $2.0-3.0$ & ESI-MS & 16 \\
\hline & & $10^{-3-10-2}$ & 3.2 & Conductivity and Stokes radii & 17 \\
\hline & & $1: 20-1: 4 *$ & $5-2.5$ & FTIR & 24 \\
\hline \multirow[t]{2}{*}{$\mathrm{LiClO}_{4}$} & PC:DMC (1:0-9) & 1 & $3.7-0.9$ & Raman & 18 \\
\hline & & $0-3$ & $1.2-1.6$ & Raman & 19 \\
\hline \multirow[t]{2}{*}{$\mathrm{LiBF}_{4}$} & $\mathrm{PC}$ & $0.1-3.0$ & $4.0-1.5$ & Raman & 20 \\
\hline & & $1: 20-1: 4^{*}$ & $4.5-2.0$ & FTIR & 24 \\
\hline LiTFSI & $\mathrm{PC}$ & $1: 20-1: 4^{*}$ & $5.3-2.5$ & FTIR & 24 \\
\hline $\mathrm{LiPF}_{6}$ & PC:DMC & $0.8-3.5$ & $5.0-2.2$ & FTIR & 23 \\
\hline \multirow[t]{3}{*}{$\mathrm{LiPF}_{6}$} & PC:DEC & $0.8-3.5$ & $4.8-2.2$ & FTIR & 23 \\
\hline & & $1.2-3.5$ & $4.2-2.7$ & IR & 11 \\
\hline & & $0.8-3.5$ & $5.2-2.5$ & FTIR & 23 \\
\hline \multirow{4}{*}{$\mathrm{LiPF}_{6}$} & $\mathrm{PC}$ & $1: 20-1: 4 *$ & $5.3-2.8$ & FTIR & 24 \\
\hline & & $0-3$ & 4.5 & TOF-neutron Diffraction $\left(\mathrm{Li}^{6} / \mathrm{Li}^{7}\right)$ & 14 \\
\hline & & $0.1-3$ & $5.1-2.3$ & Raman & 20 \\
\hline & & $0-3.2$ & $4-2.6$ & Raman, IR, MCR-analysis, computational & This work \\
\hline
\end{tabular}

negligible and it has a quantifiable effect on various physical, transport, and thermodynamic properties of the electrolyte.

In this article we revisit the electrochemical and physicochemical characteristics of $\mathrm{PC}_{-} \mathrm{LiPF}_{6}$ electrolytes. To start with, we examine the electrochemical cycling of graphite//Li cells and of cells with $\mathrm{LiNi}_{0.8} \mathrm{Co}_{0.015} \mathrm{Al}_{0.05} \mathrm{O}_{2}$ (NCA) cathodes and graphite $(\mathrm{Gr})$ anodes. After describing the ionic conductivity and electrochemistry of halfand full cells, we present a comprehensive concentration study of $\mathrm{LiPF}_{6}$ in $\mathrm{PC}$ using a combination of vibrational spectroscopy, density functional theory (DFT) and ab initio molecular dynamics (AIMD) simulations to study the $\mathrm{Li}^{+}$cation first solvation shell composition. The assignment of PC bands is mainly based on an article by Ikezawa, ${ }^{27}$ but also takes into account other assignments described in the research literature. ${ }^{15,28-32}$ These data are complemented by results from the Advanced Electrolyte Model $^{33,34}$ which is applied to determine transport properties (viscosity, conductivity, salt diffusivity, lithium transference number) in $\mathrm{PC}^{-\mathrm{LiPF}_{6}}$ electrolytes for temperatures ranging from $20{ }^{\circ} \mathrm{C}$ to $60{ }^{\circ} \mathrm{C}$ and salt concentrations up to 5 molal. AEM predictions of ion solvation properties (solvent activity, ion solvation numbers, solvent-ion energies and consequences of communal solvation, ligand-wise desolvation energy/time) for salt concentrations up to 5 molal at $30{ }^{\circ} \mathrm{C}$ and $55^{\circ} \mathrm{C}$ are also shown. In addition, results of activation energy analysis on the ion transport and ion solvation properties are presented to highlight the consequences of increasing the electrolytesalt content and raising temperature on cell performance.

Additional data that complement results presented in this manuscript are included in the Supporting Information (SI). Tables and Figures in the SI are marked with the designator S, as in Fig. S1 (available online at stacks.iop.org/JES/168/050521/mmedia).

\section{Experimental}

Electrochemical testing.-Electrochemical data were obtained both with 2032-type coin cells and from 3-electrode cells containing a $\mathrm{Li}_{\mathrm{x}} \mathrm{Sn}$ reference electrode ( $\left.\mathrm{RE}\right)$. The $\mathrm{RE}$ is used to determine relative contributions of the positive and negative electrodes to cell impedance rise; details of the reference electrode, electrode materials and cell assembly are provided elsewhere. ${ }^{35,36}$ Briefly, the graphite electrode comprised a $35 \mu \mathrm{m}$ thick coating of $92 \mathrm{wt} \%$ MAG-10 graphite and $8 \mathrm{wt} \% \mathrm{PVdF}$ binder on an $18 \mu \mathrm{m}$ thick $\mathrm{Cu}$ foil; the active material loading was $4.9 \mathrm{mg} \mathrm{cm}^{-2}$. The NCA electrode comprised a coating a mixture of 84 wt. $\% \mathrm{LiNi}_{0.80} \mathrm{Co}_{0.15} \mathrm{Al}_{0.05} \mathrm{O}_{2}$, 4 wt.\% SFG-6 graphite, 4 wt.\% acetylene black, and 8 wt.\% PVdF binder on a $30 \mu \mathrm{m}$ thick Al foil: coating thickness was $35 \mu \mathrm{m}$ and the active material loading was $8 \mathrm{mg} \mathrm{cm}^{-2}$. The electrolytes contained 1.2, 2.4, 2.8, 3.0 and 3.2 $\mathrm{M} \mathrm{LiPF}_{6}$ in PC; a commercial electrolyte, 1.2 M LiPF 6 in EC:EMC 3:7 w/w (henceforth named Gen 2), was examined for comparison. The separator was Celgard 3501 , which has a coating on a $25 \mu \mathrm{m}$ thick polypropylene film (55\% porosity) to enhance wetting by the electrolyte. After cycling, some cells were disassembled in an Ar-atmosphere glovebox; the extracted electrodes were examined by scanning electron microscopy (SEM), Raman spectroscopy, X-ray diffraction (XRD) or subjected to additional electrochemical studies.

Vibrational spectroscopy.-A series of $\mathrm{LiPF}_{6}$ in $\mathrm{PC}$ electrolytes, $0.6,1.2,2.4,2.8,3.0$, and $3.2 \mathrm{M}$, was prepared in an Ar glove box $\left(\mathrm{H}_{2} \mathrm{O}<5 \mathrm{ppm}\right)$ and kept in sealed vacuum-dried vials. All solutions were made by adding the appropriate amounts of $\mathrm{LiPF}_{6}$ and PC to the vial; homogenous solutions were achieved in a few minutes by shaking the vial vigorously. Longer times, up to $2-3 \mathrm{~h}$, were needed for the most concentrated electrolytes. FTIR spectra were obtained on the electrolytes at ambient temperature, using a PerkinElmer Spectrum 100 spectrometer with a universal Attenuated Total Reflection (UATR) module and a resolution of $4 \mathrm{~cm}^{-1}$. Raman spectra, comprising 512 interferograms (ca. $40 \mathrm{~min}$ ) at $2 \mathrm{~cm}^{-1}$ resolution, were obtained using a Bruker FT-Raman spectrometer in backscattering configuration with a $1064 \mathrm{~nm}$ excitation laser-line at a power of $200 \mathrm{~mW}$. The spectra were fitted to Voigt profiles in Matlab $^{\mathrm{TM}}$ and PeakFit ${ }^{\mathrm{TM}}$ and analysed by multivariate curve resolution (MCR) using the MCR-ALS GUI 2.0. ${ }^{37}$ Three principal components were used for both Raman and IR spectra, as more components yielded super-positioned contributions and/or were deemed non-contributing; the eigenvalue representation sum of the three components were $90 \%$ and $96 \%$ and the $\mathrm{R}^{2}$ were $99.77 \%$ and $99.90 \%$ for the Raman and IR spectra, respectively. The spectra were forced to non-negativity and without any unimodality constraint, as with locked unimodality the contribution of pure PC became zero. For normalization of the Raman spectra, we used the methyl group vibration at $958 \mathrm{~cm}^{-1}$ (Fig. S1), which provides a better internal reference than the Raman peak at $848 \mathrm{~cm}^{-1}$ used in other studies; for e.g.,. 38

To avoid complications arising from the chirality of $\mathrm{PC}^{22}$ we determined the partial $\mathrm{SN}, S N_{L i-P C}$, via the concentration of coordinated $\mathrm{PC},[\mathrm{PC}]_{\text {coord }}$, from the free $\mathrm{PC},[\mathrm{PC}]_{\text {free }}$, in relation to the total $\mathrm{PC},[\mathrm{PC}]_{\text {tot }}$, known from the composition and the salt concentration; 

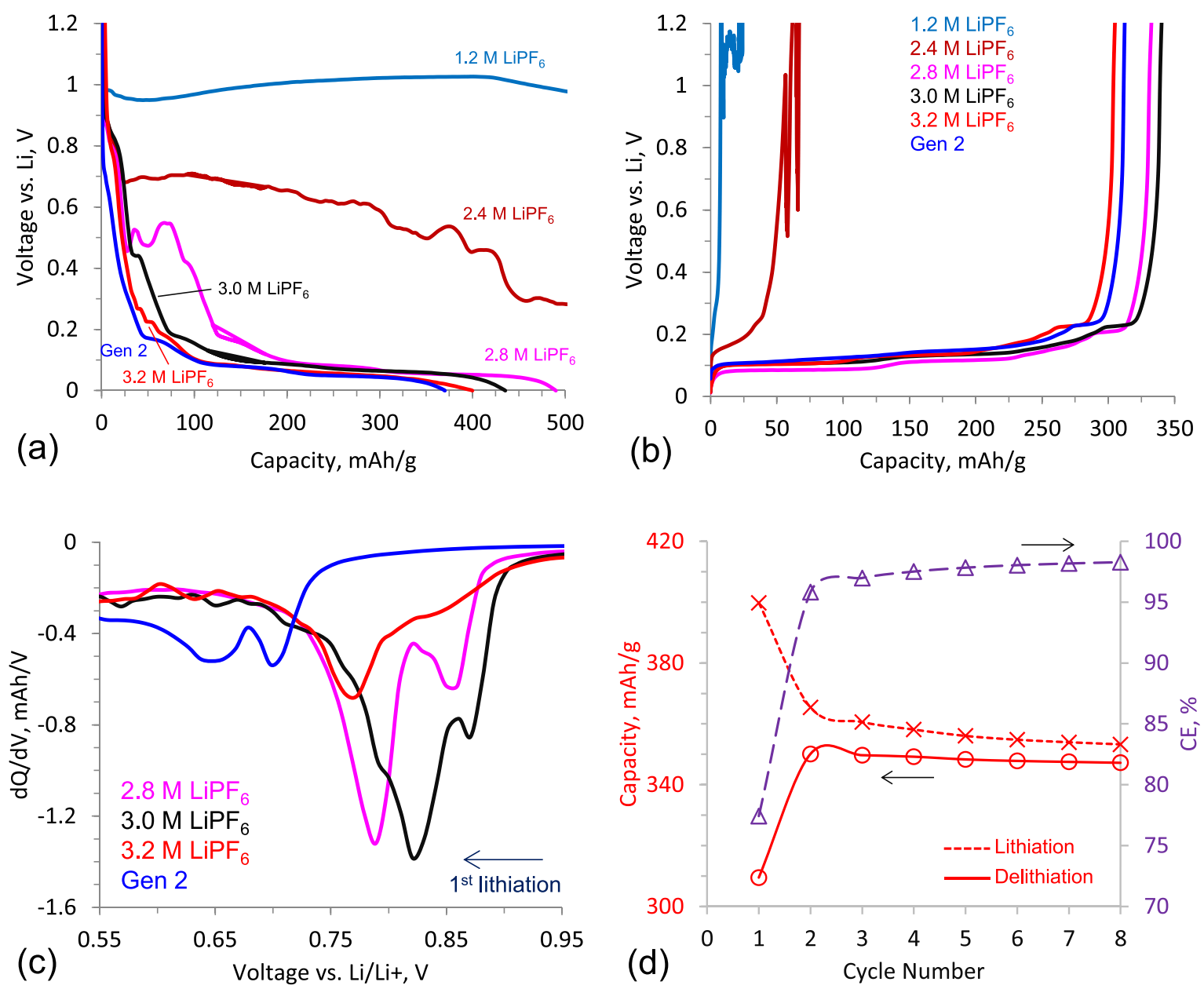

Figure 1. First cycle lithiation (a) and delithiation (b) profiles of graphite//Li cells, containing the 1.2, 2.4, 2.8, 3.0 and 3.2 M LiPF $/ \mathrm{PC}$ and Gen2 electrolytes, at $55^{\circ} \mathrm{C}$. (c) Differential capacity profiles from the 1st lithiation for some of the cells, showing peaks that arise from electrolyte reduction. (d) Lithiation and delithiation capacities, along with coulombic efficiencies (CE), for a $3.2 \mathrm{M} \mathrm{LiPF}_{6}$ graphite/Li cell cycled at $55^{\circ} \mathrm{C}$.

$$
\begin{gathered}
{[\mathrm{PC}]_{\text {coord }}=[\mathrm{PC}]_{\mathrm{tot}}-[\mathrm{PC}]_{\text {free }}} \\
S N_{L i-P C}=\frac{[P C]_{\text {coord }}}{\left[L i P F_{6}\right]} .
\end{gathered}
$$

Assuming monodentate coordination by $\mathrm{PC}$, and no sharing of PC by the $\mathrm{Li}^{+}$cations, $S N_{L i-P C}=C N_{O}$. The partial $\mathrm{SN}, S N_{L i-P F_{6}^{-}}$, can be obtained the same way,

$$
S N_{L i-P F_{6}^{-}}=\frac{\left[P F_{6}^{-}\right]_{\text {coord }}}{\left[L_{\text {iPF }}\right]}=1-\frac{\left[\mathrm{PF}_{6}^{-}\right]_{\text {free }}}{\left[\mathrm{LiPF}_{6}\right]}
$$

but also, in the conventional way of comparing integrated intensities of the peaks corresponding to free and coordinated $\mathrm{PF}_{6}{ }^{-}$, respectively. The DFT computed IR intensities and Raman activities have been used to correlate the observed areas for each species vs the number of oscillators contributing to the signal.

Computational.-DFT calculations on $\mathrm{PC}, \mathrm{Li}^{+}, \mathrm{PF}_{6}{ }^{-}, \mathrm{LiPF}_{6}$, $\left[\mathrm{LiPF}_{6}(\mathrm{PC})_{\mathrm{m}}\right]$, and $\left[\mathrm{Li}(\mathrm{PC})_{\mathrm{n}}\right]^{+}$, with $\mathrm{m}=1-3$ and $\mathrm{n}=1-4$, were carried out using the Gaussian 16 software at the M06-2X/6-311+ $+\mathrm{G}(3 \mathrm{~d}, 3 \mathrm{p})$ level of theory. ${ }^{39-41}$ The polarizable continuum model (PCM) implicit solvent model was used with EPS $=64.92$ and EPSINF $=2.01 .^{33,42,43}$ The geometries were optimized and frequency calculations performed. Following the procedure outlined in Ref. 40, the frequencies were scaled to match the experimentally observed peak at $712.3 \mathrm{~cm}^{-1}$ in pure PC. The calculated frequency of a single PC molecule with implicit solvent is $726.1 \mathrm{~cm}^{-1}$, which yields a scale factor of 0.9811 . Furthermore, the interaction energy was computed as

$$
E_{\text {complex }}=\varepsilon_{\text {complex }}-\sum_{i} \varepsilon_{i}
$$

where $\varepsilon_{\text {complex }}$ and $\varepsilon_{i}$ are the thermal corrected energies of the complex and its constituents. The energy of removing a solvent or anion from the solvation shell was computed by the difference in interaction energies.

The AIMD simulations were made as Car-Parrinello MD, ${ }^{44,45}$ for three solvent to salt ratios $(20: 1,10: 1$ and $5: 1)$, corresponding to 0.6 , 1.1 and $2.1 \mathrm{M}$. The PBE functional was used, with the dual-space Gaussian pseudo-potentials by Goedecker and coworkers, ${ }^{46-48}$ with a plane-wave cut-off of 70 Rydberg and a time step of $4 \mathrm{a}$. u. The systems were created in the CHAMPION suite ${ }^{\mathrm{TM}},{ }^{49}$ to create a random starting configuration, consisting of 1072 , 828, and 876 atoms, in periodic cubic boxes with side lengths of 22.6025 , 21.1421 , and $21.8696 \AA$, and with densities of $1.2216 \mathrm{~g} \mathrm{~cm}^{-3}$, $1.2365 \mathrm{~g} \mathrm{~cm}^{-3}$, and $1.2619 \mathrm{~g} \mathrm{~cm}^{-3}$, respectively. The systems were equilibrated until the temperature fluctuation in the systems and the radial distribution functions had converged and we deemed the local structural properties of the system to be in equilibrium. After equilibration, a Nosé-Hoover thermostat was switched on to keep the temperature at $300 \mathrm{~K}$, and subsequent production runs of 9.3, 8.2 and 10.5 ps were carried out. From the trajectories the (partial) radial 

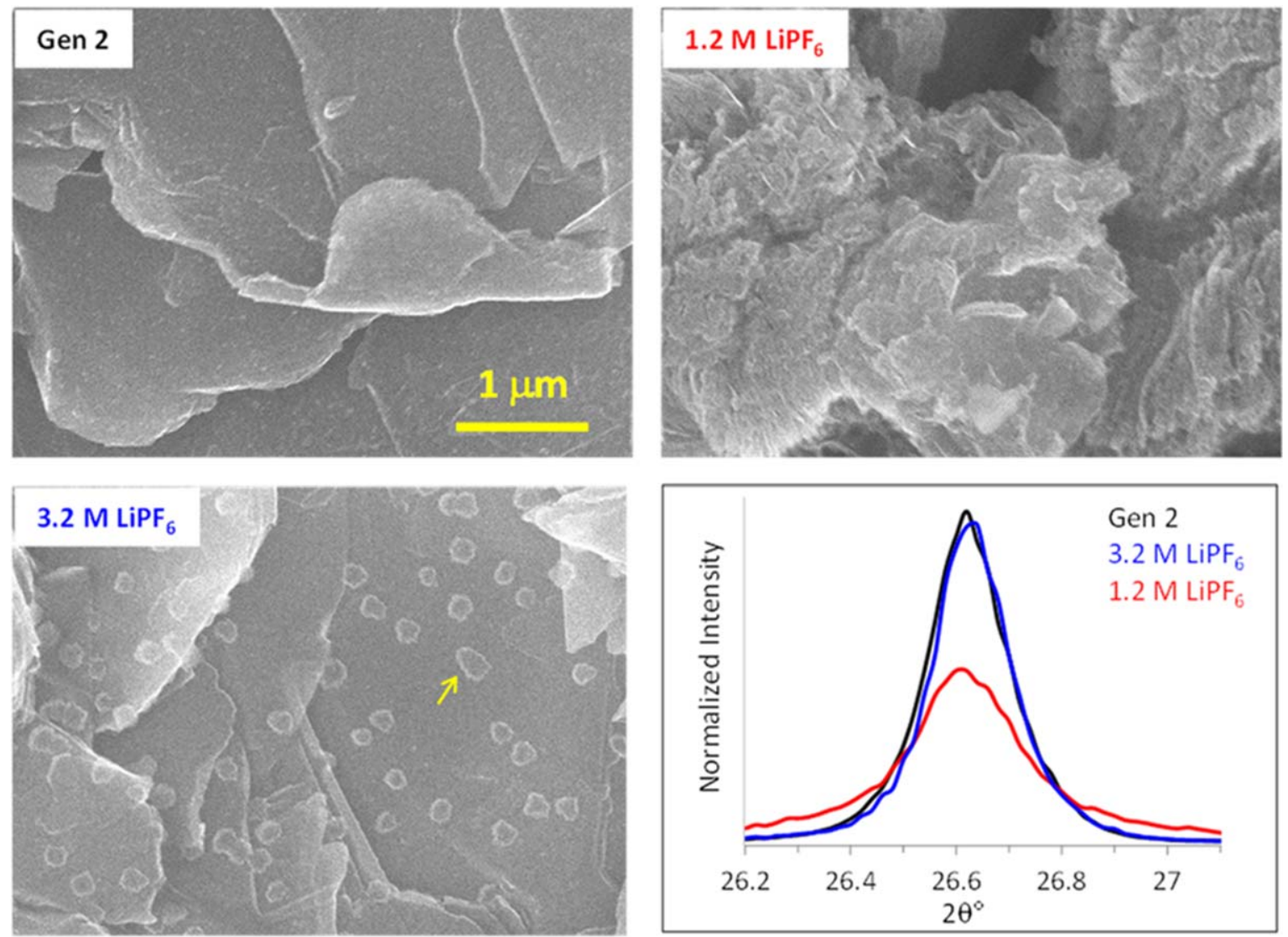

Figure 2. SEM micrographs of graphite electrodes extracted from half-cells cycled with the Gen 2, 1.2 M LiPF $\mathrm{F}_{6}$ and $3.2 \mathrm{M} \mathrm{LiPF} 6 \mathrm{electrolytes} \mathrm{LiF}_{\mathrm{F}}$ crystallites (see arrow) are seen in the $3.2 \mathrm{M} \mathrm{LiPF}_{6}$ micrograph. The bottom right panel contains XRD profiles showing the graphite (002) peak.

distribution functions (RDFs) were calculated as

$$
g_{i}(r)=\frac{n_{i}(r)}{4 \pi r^{2} \Delta r} \frac{1}{\rho_{i}}
$$

where $n_{i}(r)$ is the average number of species of type $i$ in a spherical shell of thickness $\Delta r$ at distance $r$ from the central cation, and $\rho_{i}$ is the average number density of species $i$. By integrating the (partial) RDFs, the (partial) $\mathrm{CNs}, C N_{F}$ and $C N_{N / O}$ (i.e., the number of fluorine and nitrogen/oxygen atoms in the first solvation shell) are obtained.

Advanced electrolyte model (AEM).-The chemical physics basis of AEM is found in the non-primitive non-restricted associative form of the Mean Spherical Approximation (NPNRAMSA), a form that allows the electrolyte relative permittivity to change over temperature and salt concentration, permits cations and anions to have ion sizes distinct and different from each other, as well as inclusion of property consequences tied to ion association. ${ }^{24}$ This powerful and time-efficient computational approach enables robust predictions over solvent composition, salt concentration (from 0 to past 5 molal), temperature $\left(-40{ }^{\circ} \mathrm{C}\right.$ to $\left.+80{ }^{\circ} \mathrm{C}\right)$, and relative permittivity domains (from 2 to past 100). ${ }^{50,51}$ Terms for ions, solvents, and solvated ions within the NPNRAMSA framework are molecular quantities. This allows precise accounting for the population densities and sizes of the various solvated species under the rigorous statistical mechanical approach which captures contributions from hard sphere (collisional), long-range electrostatic and short-range electrostatic interactions. Hence, a much-needed microscopic basis is provided by AEM which is also bridged to the macroscale through further chemical physics expressions that maintain connection to molecular terms. ${ }^{33,34}$ Added to this is an ionsolvation equation of state (IS-EOS) that renders values of various quantities tied to ion solvation in electrolytes, such as solvent-ion binding energies and solvation numbers; these values help quantify the energetic and kinetic costs of lithium desolvation, which are functions of composition and temperature. Regarding the salt saturation limit, AEM tracks the chemical physics of ion solvation across the salt concentration domain to determine when there are conditions present that would initiate a solid phase formation due to configurational transitions within the electrolyte. In practice, AEM outputs both concentration scales molality (m) and molarity (M). Molality is preferred for reporting because it is immune to temperature effects on density, giving benefits aimed at consistency between many computational aspects. However, the molar scale can be employed for cases where direct comparison of AEM to molarbased experimental data is desired.

\section{Results and Discussion}

Cycling in graphite//Li cells.-First-cycle capacity-voltage profiles of graphite//Li cells containing the PC electrolytes are shown in Figs. $1 \mathrm{a}$ and $1 \mathrm{~b}$; lithiation and delithiation capacities, along with coulombic efficiencies (CE), are listed in Table SI. Data from a Gen 2 electrolyte cell are also included for comparison. The profile of the 1.2 $\mathrm{M} \mathrm{LiPF}_{6}$ cell displays a long plateau at $c a .0 .9 \mathrm{~V}$ vs Li (Fig. 1a), which is consistent with continuous electrolyte reduction at the graphite electrode ${ }^{52}$ no $\mathrm{Li}^{+}$ions are inserted into the graphite electrode. For the $2.4 \mathrm{M} \mathrm{LiPF}_{6}$ cell, the electrode potential changes gradually from $c a$. $0.9 \mathrm{~V}$ to $c a$. $0.4 \mathrm{~V}$; a small capacity is observed on delithiation (Fig. 1b), which indicates some $\mathrm{Li}^{+}$insertion into the graphite. For the $2.8 \mathrm{M} \mathrm{LiPF}_{6}$ cell, bumps are seen at $c a .0 .5 \mathrm{~V}$ initially; then the potential decreases and a stable plateau below $0.1 \mathrm{~V}$ is established. Thus, the onset of suppressed graphite exfoliation is between 2.4 and $2.8 \mathrm{M}$, consistent with previous studies. ${ }^{10,11}$ For higher salt concentrations, the initial bump starts to disappear, and the graphite-staging plateaus become clearer. Differential 

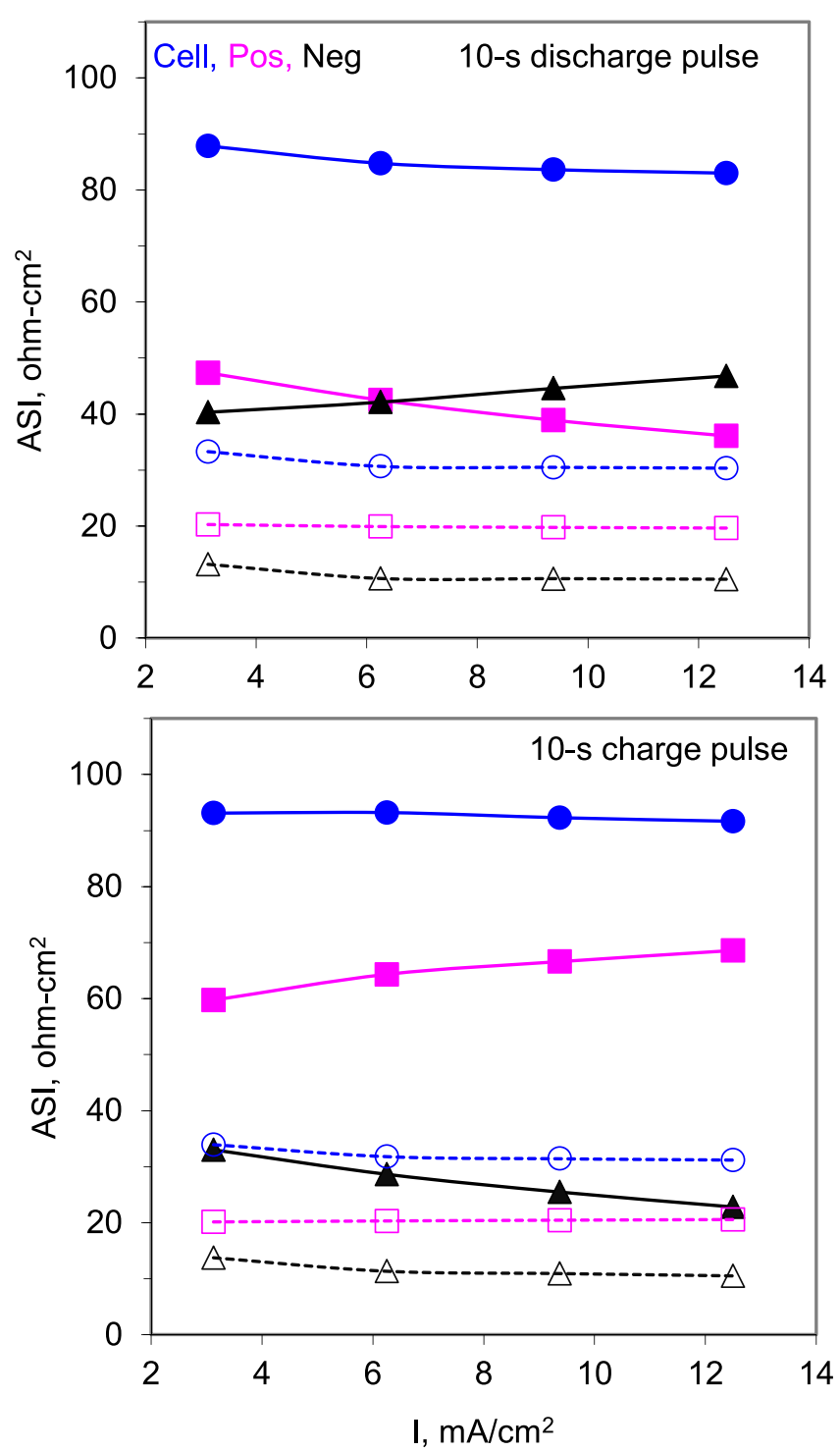

Figure 3. Impedance response of $\mathrm{NCA} / \mathrm{Gr}$ cells, containing either the Gen2 electrolyte (dashed lines) or the $3.2 \mathrm{M} \mathrm{LiPF}_{6}$ (solid lines) electrolyte, as a function of applied current. The data were obtained either with a 10-s discharge pulse (top panel) or a 10-s charge pulse (bottom panel) at a cell voltage of $3.75 \mathrm{~V}$ and at $30^{\circ} \mathrm{C}$. Data for the full cell (blue), NCA-positive electrode (magenta) and graphite-negative electrode (black) are shown. Note that during charge, $\mathrm{Li}^{+}$ions are extracted from the NCA and intercalated into the graphite; the reverse happens on discharge.

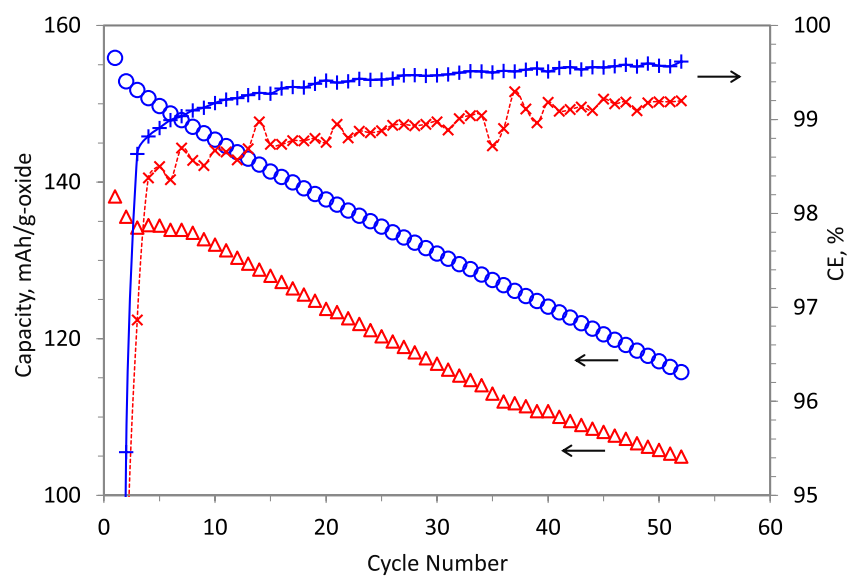

Figure 4. Cycling behavior of $\mathrm{NCA} / / \mathrm{Gr}$ cells, containing either the Gen 2 (blue) or the $3.2 \mathrm{M} \mathrm{LiPF}_{6}$ (red) electrolyte, at $55{ }^{\circ} \mathrm{C}$. The discharge capacities and coulombic efficiencies are shown on the left and right axes, respectively. The first two cycles are at a $\mathrm{C} / 20$ rate and the rest are at $\mathrm{C} / 5$ rate.

capacity profiles from the 1st lithiation (Fig. 1c) show peaks that arise from electrolyte reduction, which form solid electrolyte interphases (SEIs) on the graphite. ${ }^{11,12}$ All cells with $\mathrm{LiPF}_{6}$ concentrations $\geqslant$ $2.8 \mathrm{M}$ show delithiation capacities $>300 \mathrm{mAh} \mathrm{g}^{-1}$, comparable to that for the Gen 2 electrolyte. Cell capacities as a function of cycle number for a $3.2 \mathrm{M} \mathrm{LiPF}_{6}$ cell are shown in Fig. 1d; the coulombic efficiencies (CEs) are 77.4\% and 98.3\% (Table SII) for cycle 1 and cycle 8 , respectively, indicating parasitic side-reactions during the $55^{\circ} \mathrm{C}$ cycling.

SEM micrographs of graphite electrodes extracted from the Gen 2, 1.2 $\mathrm{M} \mathrm{LiPF}_{6}$ and 3.2 $\mathrm{M} \mathrm{LiPF}_{6}$ cells are displayed in Fig. 2. The flaky morphology of the pristine graphite is unaltered by cycling in the Gen 2 electrolyte; this is also true for graphite from the $3.2 \mathrm{M}$ $\mathrm{LiPF}_{6}$ cell. In contrast, graphite from the $1.2 \mathrm{M} \mathrm{LiPF}_{6}$ cell shows significant changes in morphology. These changes are also reflected in the XRD patterns and Raman spectroscopy data. The graphite (002) XRD profiles (Fig. 2) are similar after cycling in the Gen 2 or 3.2 $\mathrm{M} \mathrm{LiPF}_{6}$ electrolyte; the profile is less intense and broader after cycling in the $1.2 \mathrm{M} \mathrm{LiPF}_{6}$ electrolyte, indicating alterations in the graphite particles. In Raman spectroscopy of graphite, the $\mathrm{G}$ band is commonly accepted to arise from graphitic carbon, whereas D and D ' bands are linked with defects and disorder in the graphite: the $\mathrm{D}$ to $\mathrm{G}$ band intensity ratio $\left(\mathrm{I}_{\mathrm{D}} / \mathrm{I}_{\mathrm{G}}\right)$ is used to determine extent of disorder in the graphitic structure. Figure $\mathrm{S} 2$ shows that the $\mathrm{I}_{\mathrm{D}} / \mathrm{I}_{\mathrm{G}}$ values are similar for the Gen 2 and $3.2 \mathrm{M} \mathrm{LiPF}_{6}$ samples; the values are 6 to 8 greater for the $1.2 \mathrm{M} \mathrm{LiPF}_{6}$ samples, indicating significant disorder in the graphite.

Table II. Experimental FTIR bands of pure PC and 3.2 M LiPF 6 in PC solutions compared to computed frequencies of $\mathrm{PC}$ and $[\mathrm{Li}(\mathrm{PC})]^{+}$. Abbreviations: as, asymmetric; s, symmetric; sc, scissoring; wa, wagging.

PC

\begin{tabular}{lcc}
\cline { 2 - 3 } Assignment & Exp./cm & Comp. $/ \mathrm{cm}^{-1}$ \\
\hline$\nu(\mathrm{C}=\mathrm{O})(\mathrm{s})$ & 1779 & 1822 \\
$\delta \mathrm{CH}_{3}(\mathrm{sc}), \mathrm{O}-\mathrm{CH}_{2}$ (wa) & 1388 & 1404 \\
$\nu \mathrm{Ring}, \mathrm{CH}_{3}(\mathrm{wa})$ & 1353 & 1350 \\
$\mathrm{CO}_{2}(\mathrm{as})$ & 1173 & 1180 \\
$\mathrm{Ring}, \mathrm{C}-\mathrm{Me}(\mathrm{s})$ & 1074 & 1135 \\
$\mathrm{C}-\mathrm{O}(\mathrm{s})$ & 1043 & 1065 \\
Ring deformation & 774 & 786 \\
& 711 & 712
\end{tabular}

$\mathrm{Li}^{+}-\mathrm{PC}$

\begin{tabular}{cc}
\hline Exp./cm & Comp./cm \\
\hline 1750 & 1791 \\
$1391 ; 1406$ & $1399 ; 1423$ \\
1360 & 1357 \\
1200 & 1210 \\
1070 & 1142 \\
1059 & 1080 \\
781 & 789 \\
720 & 726
\end{tabular}

$\Delta_{(L i+-P C)-P C}$

\begin{tabular}{cc}
\multicolumn{2}{c}{$\Delta_{(\mathrm{Li}+-P C)-P C}$} \\
\hline Exp./cm & \multicolumn{1}{c}{ Comp./cm } \\
\hline-29 & -31 \\
$3 ; 18$ & $-5 ; 19$ \\
7 & 7 \\
27 & 30 \\
-4 & -7 \\
16 & 15 \\
7 & 3 \\
9 & 14
\end{tabular}



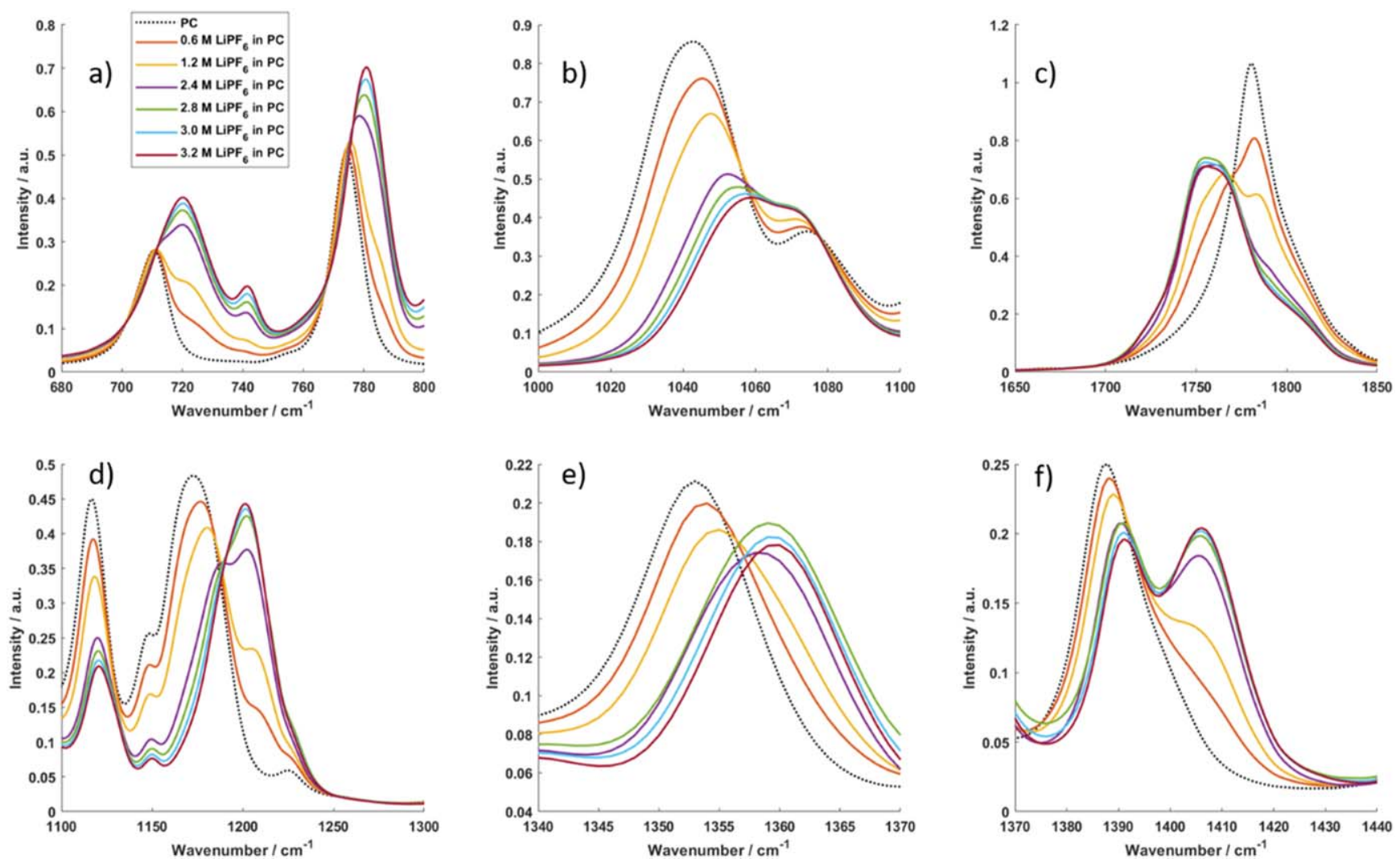

Figure 5. IR spectra of the PC electrolyte. Top panel: (a) ring vibrational modes, (b) the $\mathrm{C}-\mathrm{O}$ stretching vibrational mode and the symmetric ring $\mathrm{C}-\mathrm{CH}$ vibrational mode, and (c) the $\mathrm{C}=\mathrm{O}$ stretching vibrational mode. Bottom panel: (d) Asymmetric $\mathrm{O}-\mathrm{C}-\mathrm{O}$ mode, (e) wagging ring, $\mathrm{C}-\mathrm{CH}_{3}$ mode, (f) scissoring $\delta \mathrm{CH}_{3}$ and wagging $\mathrm{O}-\mathrm{CH}_{2}$ mode.
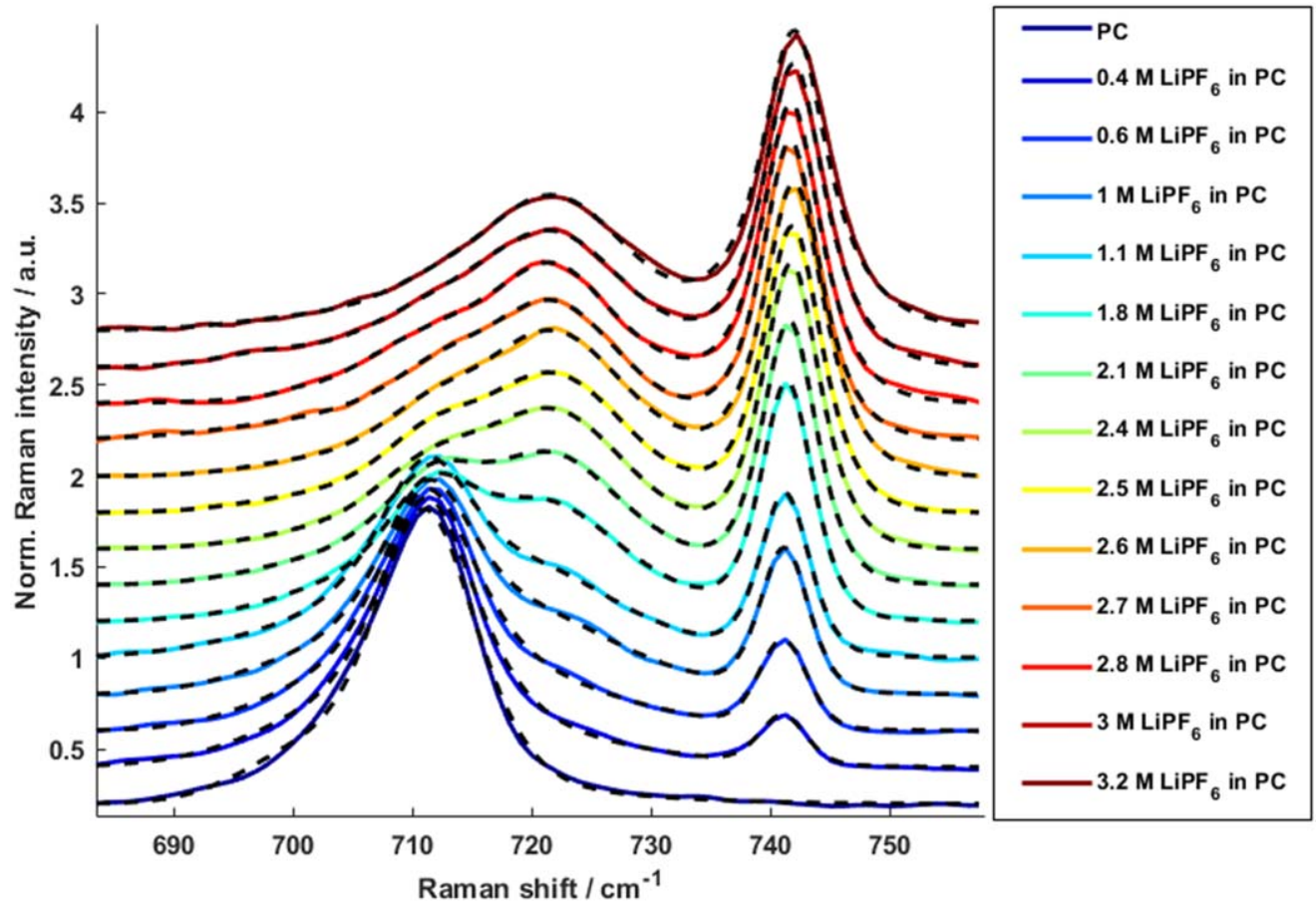

Figure 6. Raman spectra as a function of $\mathrm{LiPF}_{6}$ salt concentration in PC.

Cycling in NCA//graphite cells containing a $\mathrm{Li}_{x} \mathrm{Sn}$ reference electrode.-Capacity and impedance data were obtained on the NCA//Graphite cells after initial (formation) cycling, which comprised 3 cycles at $\mathrm{C} / 25$ rate between 3 and $4.1 \mathrm{~V}$. Area specific impedance (ASI), obtained using 10-s discharge or charge current pulses in cells containing the $\mathrm{Li}_{\mathrm{x}} \mathrm{Sn} \mathrm{RE}$, are shown in Fig. 3. Note that the electrode potential changes during the current pulse are monitored by the RE; electrode impedances can be determined by 


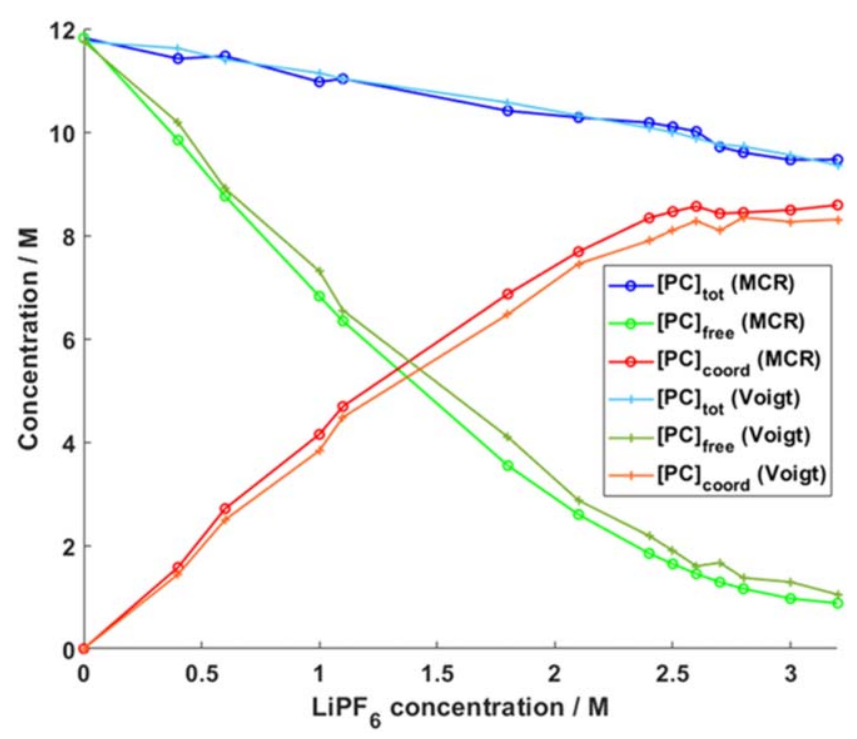

Figure 7. $[\mathrm{PC}]_{\mathrm{tot}},[\mathrm{PC}]_{\text {free }}$ and $[\mathrm{PC}]_{\text {coord }}$ as a function of $\mathrm{LiPF}_{6}$ concentration.

dividing the voltage changes by the magnitude of the applied current pulse. ${ }^{35}$ It is evident that the impedances are much higher for the 3.2 $\mathrm{M} \mathrm{LiPF}_{6}$ cell than for the Gen 2 electrolyte cell; this higher impedance is also seen in electrochemical impedance spectroscopy (EIS) spectra (Fig. S3). For the Gen 2 cell, impedances are similar for the charge and discharge pulses; furthermore, the impedances vary little with magnitude of the current pulse. In contrast, for the 3.2 $\mathrm{M} \mathrm{LiPF}_{6}$ cell, electrode impedance varies with the magnitude and direction of the current pulse. During the 10-s discharge pulse, the positive electrode impedance decreases, while the negative electrode impedance increases, as the pulse-current magnitude increases. The reverse is seen for the 10-s charge pulse: negative electrode impedance decreases, while positive electrode increases as the current increases. In addition, for the charge pulse, magnitude of the positive impedance is significantly greater than that of the negative impedance; for the discharge pulse, values of the positive and negative electrode impedance are similar. The differences between the discharge and charge pulse data indicate that the solvation/desolvation behavior of $\mathrm{Li}^{+}$ions is very different in the Gen 2 and 3.2 $\mathrm{M} \mathrm{LiPF}_{6}$ electrolytes.

Cell and electrode impedances decrease with increasing temperature (Fig. S4). To improve cell kinetics and to quickly reveal any instabilities, cells with the Gen 2 and 3.2 $\mathrm{M} \mathrm{LiPF}_{6}$ electrolytes were cycled at $55{ }^{\circ} \mathrm{C}$; the data are shown in Fig. 4. Although the cycling trends are similar, delithiation capacities and coulombic efficiencies are consistently lower for the $3.2 \mathrm{M} \mathrm{LiPF}_{6}$ cell; these lower values could be a consquence of its relatively higher impedance and the differences in charge/discharge behavior mentioned earlier. The graphite electrodes, harvested from both types of cells after cycling, showed no exfoliation indicating compatibility of the graphite with the concentrated PC electrolyte.

Does the SEI formed with the 3.2 $\mathrm{M} \mathrm{LiPF}_{6}$ electrolyte protect the graphite from solvent intercalation ? To answer this question, we prepared multiple NCA//Graphite cells and cycled them $(\mathrm{C} / 25$ cycles, 3-4.1 V) in the 3.2 $\mathrm{M} \mathrm{LiPF}_{6}$ electrolyte. Then we harvested the graphite electrodes from these cells and prepared Graphite//Li cells with the $1.2 \mathrm{M} \mathrm{LiPF} / \mathrm{PC}$ electrolyte in an Ar-atmosphere glovebox. Cycling profiles of these latter cells resembled those of cells prepared with fresh graphite electrode (Fig. 1a); the SEI formed by the $3.2 \mathrm{M} \mathrm{LiPF}_{6}$ electrolyte did not protect the graphite from exfoliation. That is, the cycling capability of the 3.2 $\mathrm{M} \mathrm{LiPF}_{6}$ cell does not result from an enhanced SEI. Rather, the behavior is a consequence of $\mathrm{Li}^{+}$(de)solvation behavior, which is explored below.

Ionic conductivity.-Data for the $1.2 \mathrm{M} \mathrm{LiPF}_{6}, 3.2 \mathrm{M} \mathrm{LiPF}_{6}$ and Gen 2 electrolytes as a function of temperature are shown in Fig. S5. While the ionic conductivities of Gen 2 and $1.2 \mathrm{M} \mathrm{LiPF}_{6}$ solutions change little with temperature, the $3.2 \mathrm{M} \mathrm{LiPF}_{6}$ solution shows a strong temperature dependence. At $30{ }^{\circ} \mathrm{C}$, ionic conductivity of the 3.2 $\mathrm{M} \mathrm{LiPF}_{6}$ solution is about $1 \mathrm{mS} \mathrm{cm} \mathrm{cm}^{-1}$, roughly an order of magnitude lower than that of Gen 2. The $\mathrm{Li}^{+}$ion transport mechanism has been shown to strongly depend on the salt concentration, and the cation transference number increases with concentration. Differences in ionic conductivities between the various solutions apparently originate from altered cation-solvent and cation-anion interactions, and points to the need for a better understanding of the local structure as a function of salt concentration for the HCEs. ${ }^{53-57}$

Vibrational spectroscopy complemented by DFT and AIMD simulations.-We start by focusing on the cation-solvent interactions. Comparing the IR spectra of pure PC and $\mathrm{LiPF}_{6}$ in $\mathrm{PC}$ and employing the corresponding DFT calculations, we reveal that several PC peaks are affected by the addition of salt (Fig. 5 and Table II). Overall, the DFT calculations qualitatively reproduce the observed spectra and quantitatively replicate the frequency shifts within a few wavenumbers. The two PC peaks at $711 \mathrm{~cm}^{-1}$ and $770 \mathrm{~cm}^{-1}$, as well as the $\mathrm{C}-\mathrm{O}$ symmetric stretching at $c a$.
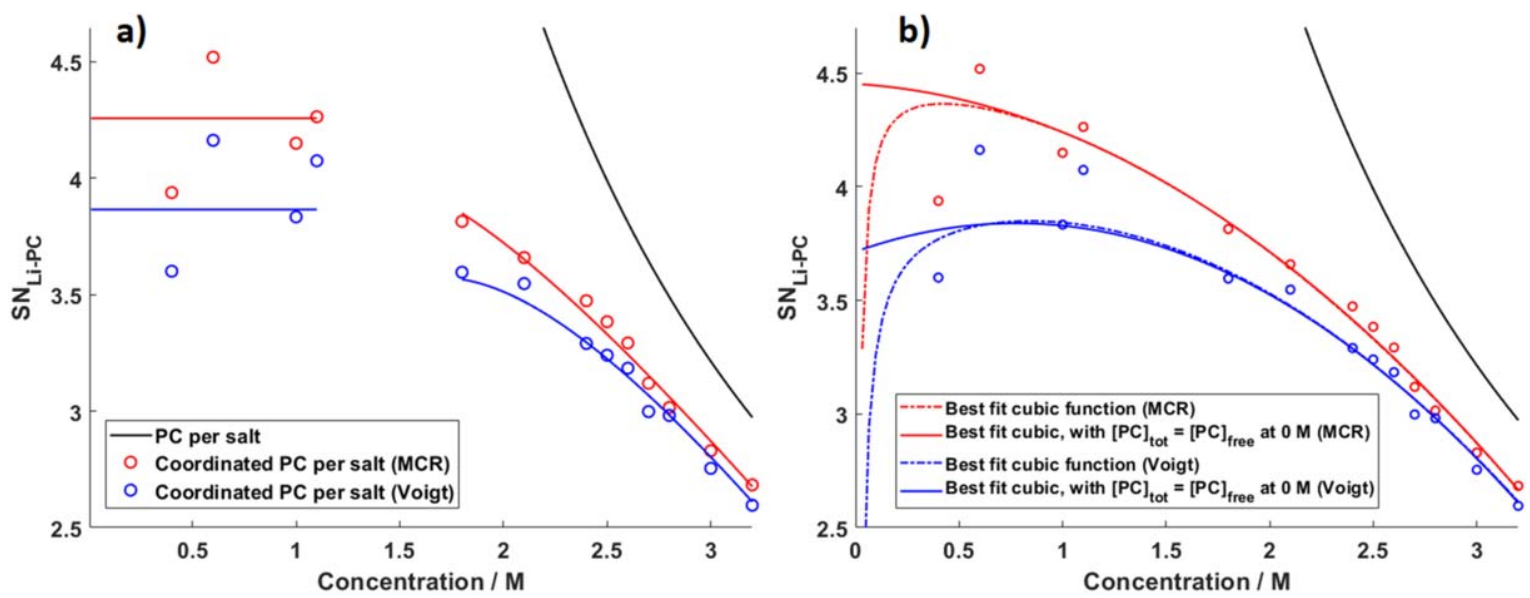

Figure 8. $\mathrm{SN}_{\mathrm{Li}-\mathrm{PC}}$ as a function of salt concentration: (a) derived from a linear fit to $[\mathrm{PC}]_{\text {free }}$ in the conventional regime and a parabola in the concentrated regime, and (b) with a cubic fit to $[\mathrm{PC}]_{\text {free }}$. The black line shows the number of $\mathrm{PC}$ molecules per $\mathrm{Li}^{+}$ion. 

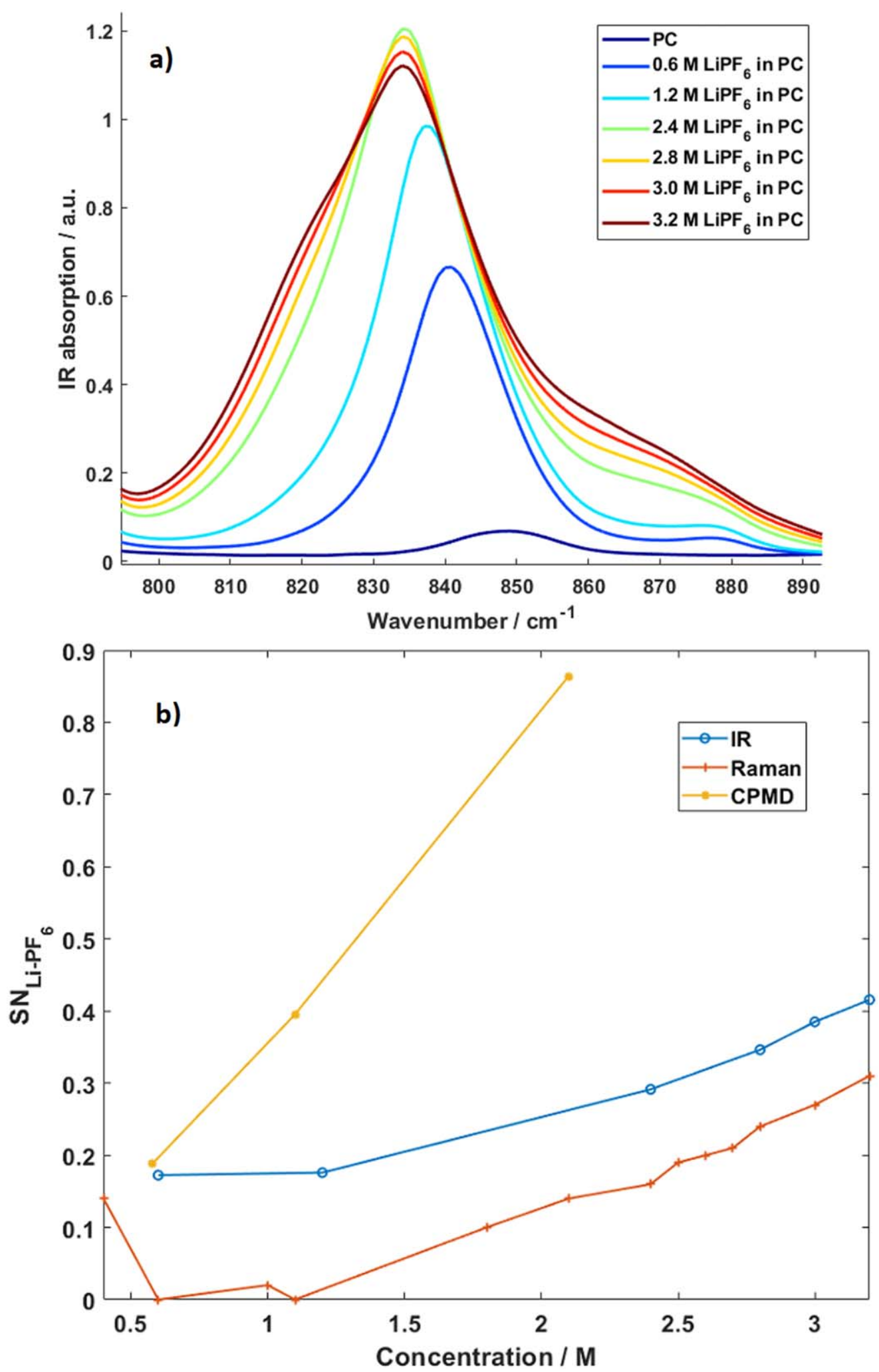

Figure 9. IR spectra in the ring-breathing mode region (a) and number of anions in the first solvation shell as a function of salt concentration (b) determined from IR, Raman and Car-Parrinello MD simulations.

$1040 \mathrm{~cm}^{-1}$, all shift to higher wavenumbers with increasing salt concentration alongside an additional anion peak at $c a .740 \mathrm{~cm}^{-1}$ (Figs. 5a and 5b). With increasing salt concentration, the characteristic $v(\mathrm{C}=\mathrm{O})$ PC band shows at least one new peak in the $1750-1770 \mathrm{~cm}^{-1}$ range due to $\mathrm{Li}^{+}-\mathrm{PC}$ interactions with the carbonyl oxygen (Fig. 5c). The asymmetric $\mathrm{O}-\mathrm{C}-\mathrm{O}$ mode at
$1173 \mathrm{~cm}^{-1}$ sees a large shift of almost $30 \mathrm{~cm}^{-1}$ (Fig. 5d), and the peak at $1353 \mathrm{~cm}^{-1}$ shifts to $1360 \mathrm{~cm}^{-1}$ (Fig. 5e), while the peak at $1388 \mathrm{~cm}^{-1}$ shrinks and gains a large shoulder at $1406 \mathrm{~cm}^{-1}$ (Fig. 5f). The band shapes and intensities are very similar for $>2.4 \mathrm{M} \mathrm{LiPF}_{6}$; the broad bands indicates multiple vibrational frequencies arising from various $\mathrm{Li}_{\mathrm{x}}(\mathrm{PC})_{\mathrm{y}}$ species. 


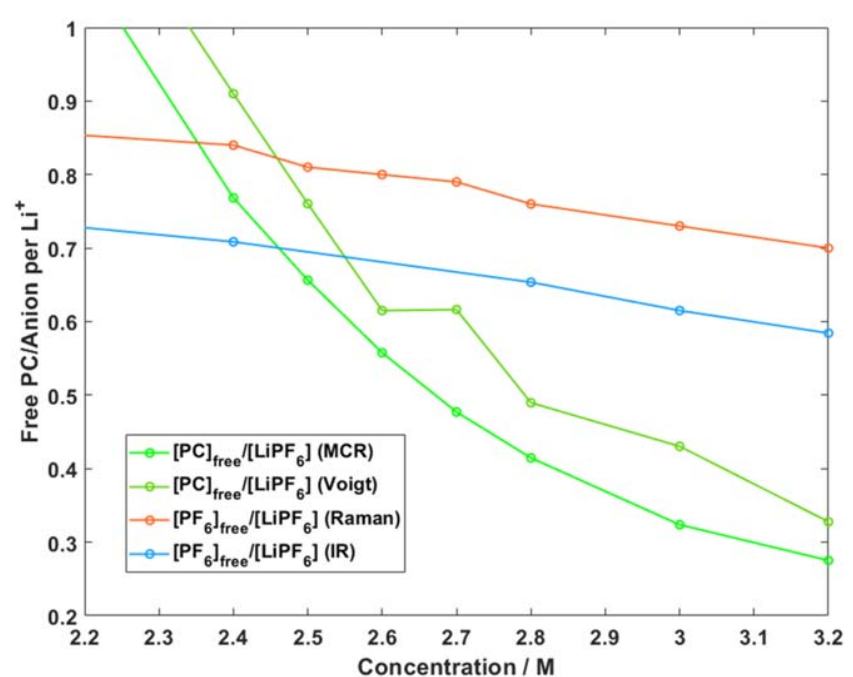

Figure 10. Concentration of free $\mathrm{PC}$ and free $\mathrm{PF}_{6}{ }^{-}$anions per $\mathrm{Li}^{+}$as a function of salt concentration.

For the same vibrations in the Raman spectra, starting from the above assignments, shifts and calculated frequencies, we fit all the $\mathrm{PC}^{-\mathrm{LiPF}_{6}}$ spectra in the $680-760 \mathrm{~cm}^{-1}$ range to 3 Voigt profiles centred at $712 \mathrm{~cm}^{-1}, 721 \mathrm{~cm}^{-1}$ and $742 \mathrm{~cm}^{-1}$, which are associated with free $\mathrm{PC}$, coordinated $\mathrm{PC}$, and $\mathrm{PF}_{6}{ }^{-}$, respectively (Fig. 6). Both the conventional and MCR analysis give similar results, with only a slight (ca. 0.2) higher $S N_{L i-P C}$ for the latter (Figs. 7 and 8). Figure 7 shows that as a function of salt concentration $[\mathrm{PC}]_{\text {tot }}$ decreases linearly, while $[\mathrm{PC}]_{\text {free }}$ has a more complicated behaviour. Although a parabola gives a very good fit to the $[\mathrm{PC}]_{\text {free }}$ data (Fig. S6), this fitting produces a peak in $S N_{L i-P C}$ at $c a$. $0.5 \mathrm{M}$ and a sharp drop at lower concentrations resulting in a negative $S N_{L i-P C}$ at $c a .0 .2 \mathrm{M}$. This behaviour is not likely, as at low concentrations there should only be a weak concentration dependence. Forcing $[P C]_{t o t}=[P C]_{\text {free }}$ for pure PC we find $S N_{L i-P C}$ to change linearly, but with a poor resulting fit. To resolve this dilemma, we suggest two possibilities: either $[P C]_{\text {free }}$ behaves as a cubic function, with $[P C]_{\text {tot }}=[P C]_{\text {free }}$ enforced at $0 \mathrm{M}$, or there are two regimes-one conventional and one concentrated. For the latter possibility, in the conventional regime we use

$$
\begin{gathered}
{[P C]_{\text {free }}=k\left[\operatorname{LiPF}_{6}\right]+m} \\
{[P C]_{\text {total }}=k^{\prime}\left[\mathrm{LiPF}_{6}\right]+m^{\prime}}
\end{gathered}
$$

where $k, k^{\prime}, m$ and $m^{\prime}$ are constants (Table SIII). For pure PC $[P C]_{\text {free }}$ $=[P C]_{\text {total }}$ and hence $m=m^{\prime}$, and thus $S N_{L i-P C}=k^{\prime}-k$ is constant. In the concentrated regime $[P C]_{\text {free }}$ is described by

$$
[P C]_{\text {free }}=\mathrm{p}\left[\mathrm{LiPF}_{6}\right]^{2}+\mathrm{q}\left[\mathrm{LiPF}_{6}\right]+\mathrm{r},
$$

and

$$
S N_{L i-P C}=-p\left[\mathrm{LiPF}_{6}\right]+\frac{m^{\prime}-r}{\left[\mathrm{LiPF}_{6}\right]}+k^{\prime}-q .
$$

The inverse dependence on the salt concentration is very weak, except for the transitions from one regime to the other. This happens between $1.1 \mathrm{M}-1.8 \mathrm{M}$. In contrast, at $>2.4 \mathrm{M}, S N_{L i-P C}$ decreases linearly (Fig. 8); this might be the true behaviour of $S N_{L i-P C}$ in the concentrated regime. For this to be the case, however, $[P C]_{\text {free }}$ must still follow a parabola in the concentrated regime and $\mathrm{m}^{\prime}=\mathrm{r}$, for which there are no apparent a priori reasons. Overall, the $S N_{L i-P C}$ range is from 4.5 down to 2.6 (Fig. 8) in agreement with literature reports. ${ }^{11,20,26,58}$ Figure 7 indicates that at ca. $2.3 \mathrm{M}$ there is less than one free $\mathrm{PC}$ per $\mathrm{Li}^{+}$and at the highest concentration of $3.2 \mathrm{M}$, there is only $c a$. 0.3 free $\mathrm{PC}$ per $\mathrm{Li}^{+} ;[P C]_{\text {free }}$ never reaches zero, which is often indicated as a defining feature of an HCE. Looking at the

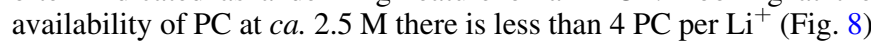
and communal solvation is a must to fill the first solvation shell of $\mathrm{Li}^{+}$without any contributions from $\mathrm{PF}_{6}{ }^{-}$.

In the Raman spectra, the non-linear decrease in the P-Fstretching mode at $742 \mathrm{~cm}^{-1}$ can be attributed to ion-pairing. This attribution is corroborated by evolution of the $840 \mathrm{~cm}^{-1}$ mode in the IR spectra (Fig. 9a), which shifts to lower wavenumbers and broadens displaying a shoulder on the high frequency side as a function of increasing salt concentration. Using IR peaks in the $800-890 \mathrm{~cm}^{-1}$ region we find that $40 \%$ of $\mathrm{Li}^{+}$have $\mathrm{PF}_{6}^{-}$anions in
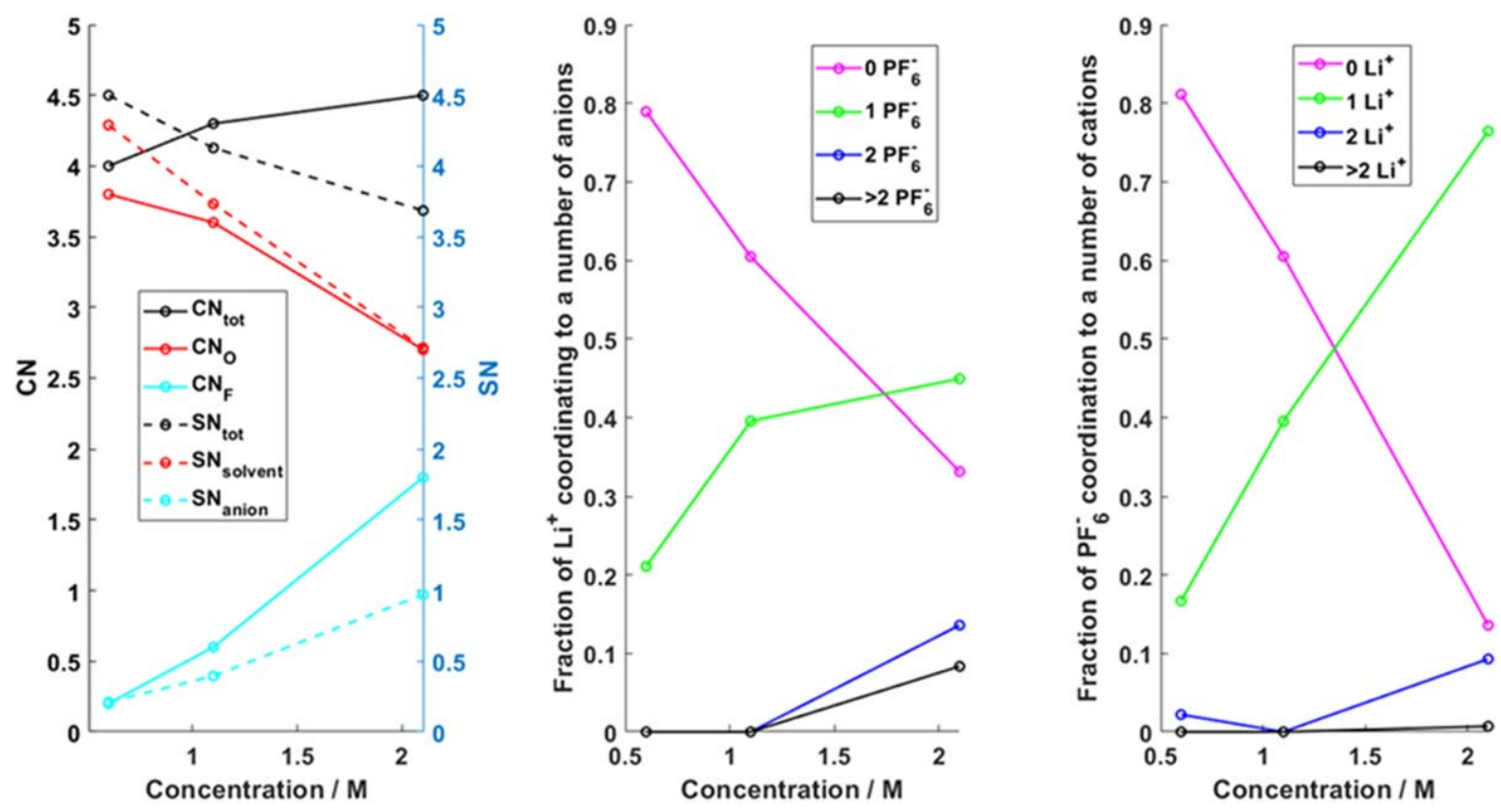

Figure 11. Results of AIMD simulations. (Left panel) CNs and SNs as a function of $\mathrm{LiPF}_{6}$ concentration; (middle panel) fraction of cations with $0,1,2$ or more anions in its solvation shell as a function of salt concentration; (right panel) fraction of anions with $0,1,2$ or more cations as immediate neighbours as a function of salt concentration. 

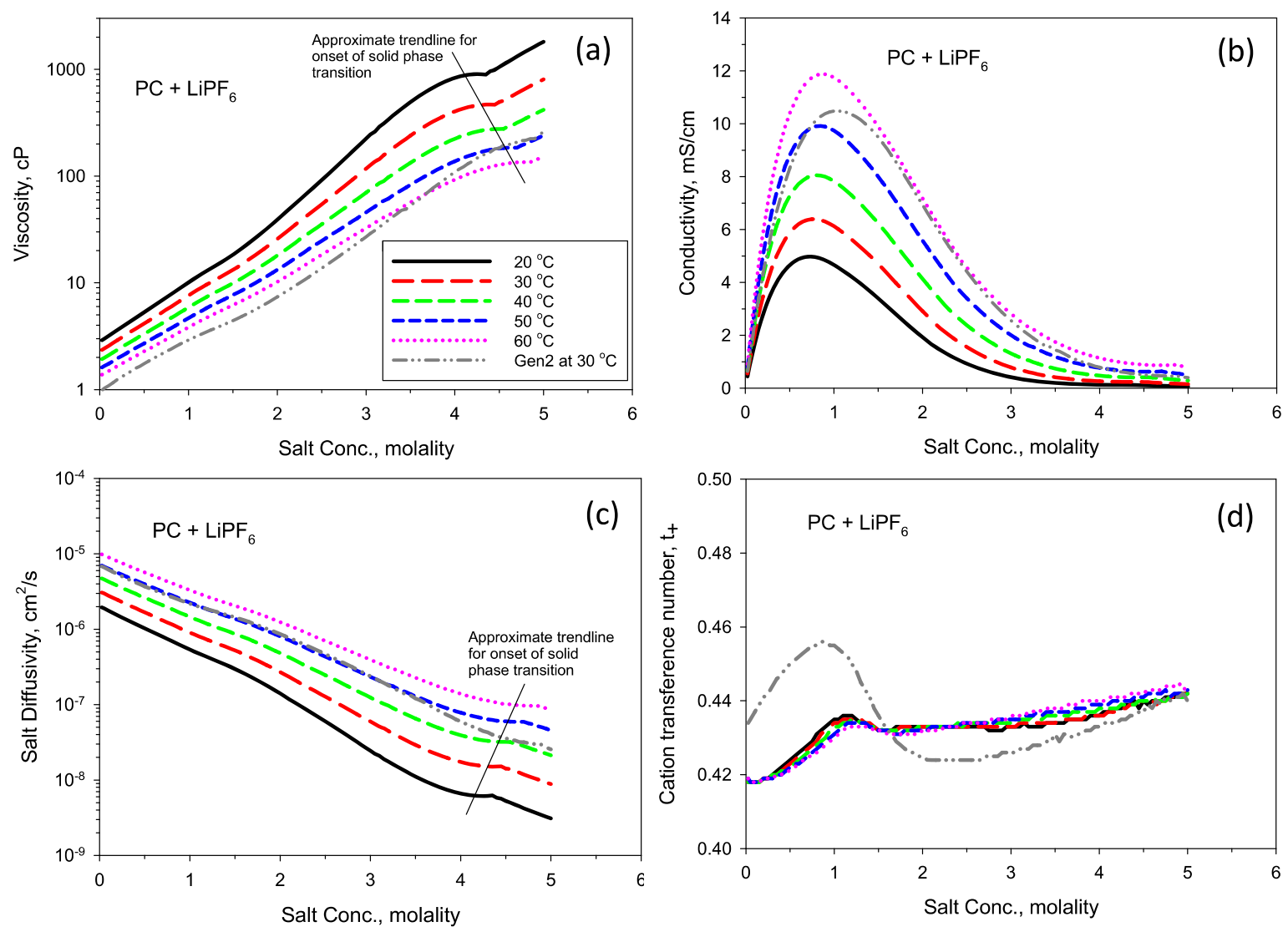

Figure 12. AEM-predicted transport properties for the $\mathrm{PC}-\mathrm{LiPF}_{6}$ system at $20{ }^{\circ} \mathrm{C}$ to $60{ }^{\circ} \mathrm{C}$ covering (a) viscosity, (b) conductivity, (c) salt diffusivity, and (d) lithium transference number, $\mathrm{t}_{+}$. Values at $30^{\circ} \mathrm{C}$ for the Gen 2 electrolyte system are given for comparison.

the first solvation shell (Fig. 9b) at 3.2 $\mathrm{M} \mathrm{LiPF}_{6}$. Note, however, that DFT calculations indicate that the $840 \mathrm{~cm}^{-1}$ peak is not only due to free $\mathrm{PF}_{6}{ }^{-}$, but also has contributions from the CIPs (Fig. S7). For the Raman data, applying a cross-section correction factor of 1.11 to account for the lower polarizability, we find that even at $3.2 \mathrm{M}$ only $30 \%$ of the $\mathrm{Li}^{+}$have $\mathrm{PF}_{6}^{-}$anions in their first solvation shell, forming contact-ion pairs (CIPs). Comparing $[P C]_{\text {free }} /\left[L i P F_{6}\right]$ and $\left[\mathrm{PF}_{6}^{-}\right]_{\text {free }} /\left[\mathrm{LiPF}_{6}\right]$, the concentration of free anions becomes greater than the concentration of free solvent between $2.4 \mathrm{M}$ and $2.6 \mathrm{M}$ (Fig. 10), which corresponds well with the experimentally observed suppression of PC-associated graphite exfoliation at $>2.4 \mathrm{M}$.

From AIMD simulations (Fig. S8) we find the following: (i) there is a clear trend of increasing anion relative to solvent contribution to the first solvation shell of $\mathrm{Li}^{+}$as a function of salt concentration, and (ii) the partial $\mathrm{Li}^{+} \mathrm{CNs}$ (Fig. 11) show that for the highest salt concentration (5:1) most $\mathrm{Li}^{+}$are in direct contact with an anion. For the $10: 1$ system $\mathrm{ca}$. $40 \%$ of the solvation shells contain an anion; further increasing the salt concentration solvation shells with more than one anion are obtained, indicating formation of large ionic aggregates at concentrations $\geqslant 2.0 \mathrm{M} \mathrm{LiPF}_{6} \cdot{ }^{26}$ Moreover, the ratio of $C N_{F}$ and the average number of anions in the first solvation shell approaches 2 , clearly indicating bidentate coordination of $\mathrm{PF}_{6}{ }^{-}$, in agreement with the energetic picture arising from the DFT calculations (Fig. S9). This, in turn, breaks the degeneracy of some of the $\mathrm{PF}_{6}{ }^{-}$modes, producing two different frequency shifts for the $\mathrm{F}-\mathrm{P}$ bonds containing the fluorine atoms coordinating to the $\mathrm{Li}^{+}$cation and the two orthogonal F-P bonds (Fig. S7). By deconvoluting the $\mathrm{Li}^{+}-\mathrm{O} \mathrm{RDF}$ into the contributions from ether oxygen atoms and carbonyl oxygen atoms (Fig. S8) it is clear that PC also coordinates $\mathrm{Li}^{+}$in a bidentate manner, ${ }^{59}$ although the latter is not the dominant mode of coordination.
Comparing the experimentally and the computationally derived $S N_{L i-P F 6}$ and $S N_{\text {anion }}$ is not straightforward. The ratio $\left[P F_{6}^{-}\right]_{\text {coord }} /$ [LiPF 6 should be compared with $S N_{\text {anion }}$, but this measure fails to account for any anions being shared between several cations and/or several cations sharing an anion, and the different effects on the $\mathrm{CN}$ and SN. ${ }^{20,26}$ Thus, the Raman and IR measurements likely underestimate the amounts of anions in the shells; note that the fraction of coordinated anions is an inappropriate proxy for $S N_{\text {anion }}$ at high salt concentrations. The AIMD simulation results, however, might overestimate the amount of anions in the solvation shells because the short production runs (picoseconds) are unlikely to break apart any CIPs present in the starting configuration(s).

Moving to the nature and strength of the interactions, structures without any anions in the first cation solvation shell are most energetically stable (Fig. S9). Hence, when there is a surplus of PC the preferred solvation shell will consist of 4 PC molecules. As salt concentration increases, the formation of CIPs becomes nonnegligible: as there is already less solvent in the solvation shell, and anion-containing solvation shells are less stable, the energy required to remove a solvent and/or anion out of the shell is reduced. Thus, with anions in the first solvation shell of $\mathrm{Li}^{+}$, the process of stripping all the solvents and anions from the solvation shell is easier in the highly concentrated electrolyte ${ }^{56,57}$ and improved kinetics can be expected, both in the bulk electrolyte and at the electrolyte/ electrode interfaces. ${ }^{60,61}$

Observations from the AEM study.-Ion transport properties of the $\mathrm{PC}-\mathrm{LiPF}_{6}$ electrolytes are shown in Fig. 12. Viscosity of the electrolyte solutions increases (Fig. 12a), while salt diffusivity decreases (Fig. 12c), with increasing $\mathrm{LiPF}_{6}$ concentration; higher temperatures lower the viscosities and elevate the diffusivities. The 

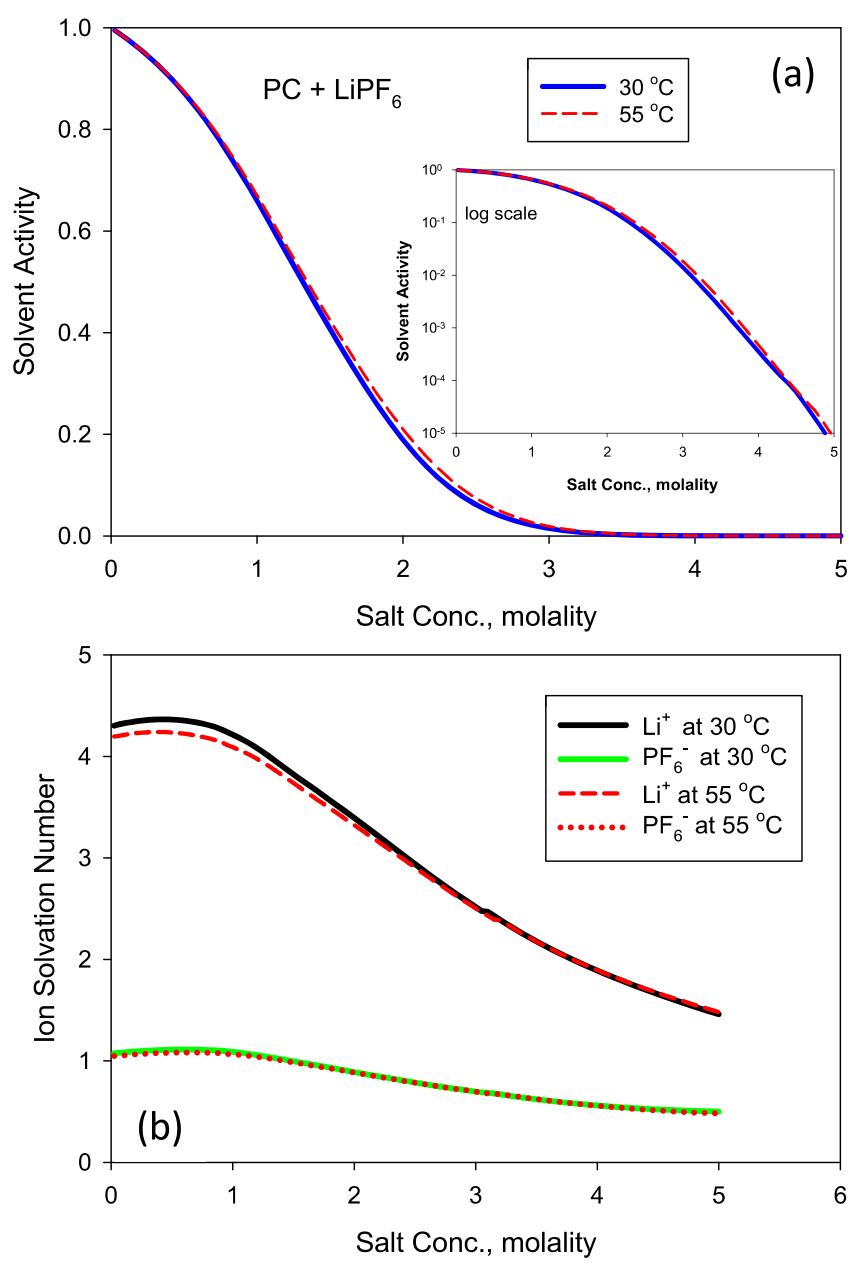

Figure 13. Solvent activity (a) and ion-solvation numbers (b) predicted by AEM for $\mathrm{PC}-\mathrm{LiPF}_{6}$ at $30{ }^{\circ} \mathrm{C}$ and $55^{\circ} \mathrm{C}$.

trendlines shown in Figs. 12a, 12c indicate that the onset of a solid phase transition, likely due to solid solvate formation, is a function of temperature and starts to occur at around 4.3 molal at $30{ }^{\circ} \mathrm{C}$, which compares favourably with the "nearly saturated" solution of 4.45 molal $\mathrm{LiPF}_{6}$ in $\mathrm{PC}$ reported by Aoki et al.. ${ }^{12}$ Electrolyte conductivities (Fig. 12b) increase, reach a maxima, then decrease with increasing salt concentrations; the salt concentrations at these maxima increase with temperature $\left(0.73 \mathrm{M}\right.$ at $20{ }^{\circ} \mathrm{C}$ and $0.91 \mathrm{M}$ at $60{ }^{\circ} \mathrm{C}$ ). Values at $30{ }^{\circ} \mathrm{C}$ for the Gen 2 electrolyte, given for comparison, indicate that the lower viscosity of this electrolyte plays a central role in improving conductivity and diffusivity to where values at $30{ }^{\circ} \mathrm{C}$ are comparable to those of the PC-LiPF 6 system at roughly $50{ }^{\circ} \mathrm{C}-55{ }^{\circ} \mathrm{C}$.

The cation transference number $\left(t_{+}\right)$, which is the fraction of the ionic conductivity attributable to $\mathrm{Li}^{+}$, increases (in general) with salt concentration; the values only show a minor temperature-dependence (Fig. 12d). The behaviour of $t_{+}$for PC-LiPF 6 is linked to the relative change of solvated cation and anion diameters over salt concentration. Overall, the cation solvated diameter decreases more over concentration than that of the anion, causing cationic conductivity to increase at a higher rate than its anionic counterpart. For the Gen 2 electrolyte, the $t_{+}$values are also affected by the preferential ion solvation of EC over EMC. Note that the $\mathrm{Li}^{+}$ transference number for more concentrated $\mathrm{PC}-\mathrm{LiPF}_{6}$ electrolytes is higher than that of the Gen2 electrolyte, which in principle should enable faster charging and allow higher power densities for cells containing the former. However, these cell properties are also determined by characteristics of the electrode-electrolyte interfaces.
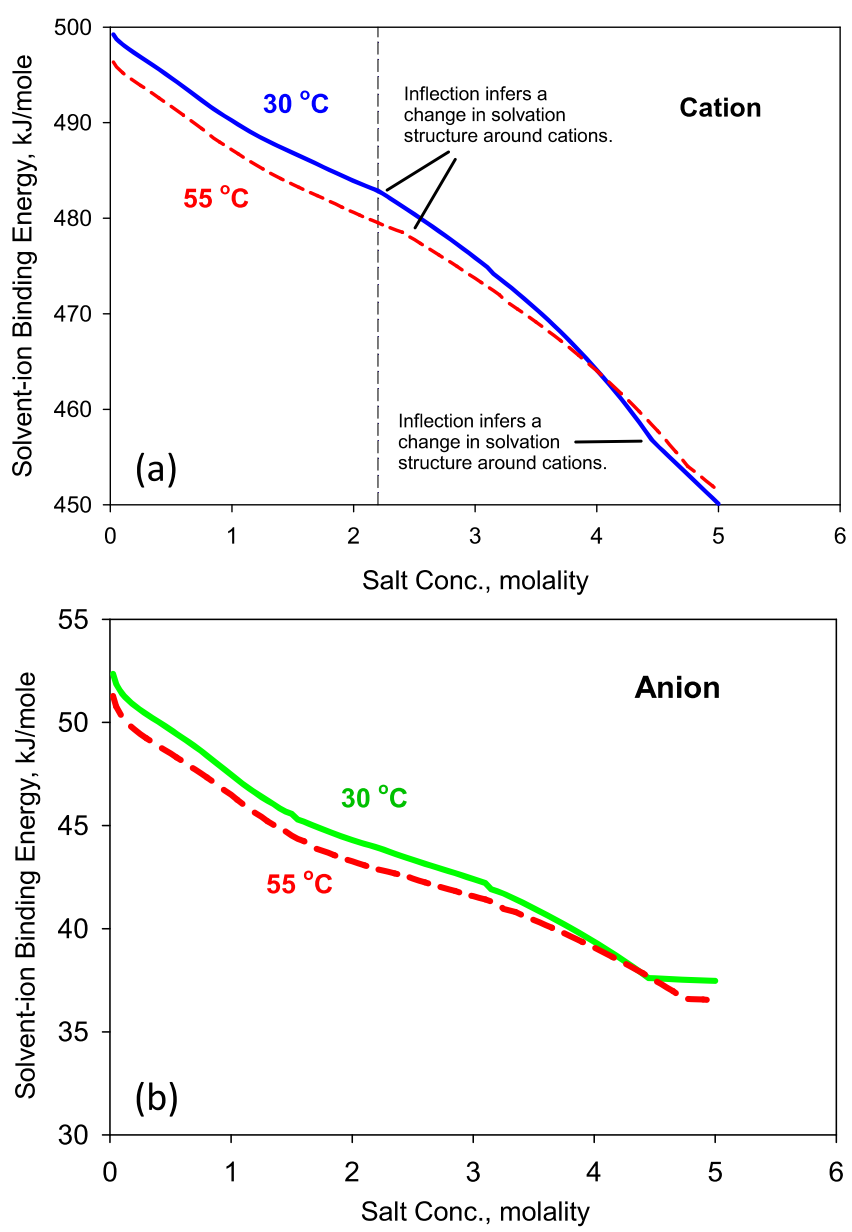

Figure 14. Average solvent-ion binding energies for $\mathrm{PC}^{-\mathrm{LiPF}_{6}}$ at $30{ }^{\circ} \mathrm{C}$ and $55{ }^{\circ} \mathrm{C}$ for the cations (top panel) and anions (bottom panel).

The highly inorganic surface films formed on the oxide and graphite electrodes in $\mathrm{LiPF}_{6}$ based $\mathrm{HCEs}^{12}$ are very likely responsible for their higher impedance relative to those cycled in the Gen 2 electrolyte (Figs. 3, S3).

Ion solvation properties of the electrolytes are shown in Figs. 13-16. The solvent activity (Fig. 13a) is a thermodynamic term that represents the relative availability of solvent to participate in associative or reactive processes. Solvent activity is derived from values of the osmotic coefficient at each salt concentration. A sigmoidal shape is observed, wherein decreasing values over salt concentration indicate lesser solvent availability due to more and more solvent participating in ion solvation. Solvent activity is slightly higher at $55{ }^{\circ} \mathrm{C}$ than $30{ }^{\circ} \mathrm{C}$ due to less-extensive ion solvation (hence, more solvent availability) at the elevated temperature, where increased molecular collision rates act to moderate and lessen ion solvated diameters. At around 3.4 molal $(3.28 \mathrm{M})$ the solvent activity has a value of 0.0035 at $30{ }^{\circ} \mathrm{C}$ indicating that less than one percent of solvent is "free" and not participating in any form of ion solvation; this conclusion is in accord with the spectroscopy analysis discussed earlier (Fig. 7). The relative lack of PC solvent molecules, available for electrolyte reduction (or oxidation) reactions at the graphite (or oxide) surfaces, explains the lower proportion of organic components in the electrode surface films. ${ }^{12}$ Comparison of results from various methods to determine solvent availability (MCR, Voigt, AEM) are given in Fig. S10, which indicates excellent agreement between the general trends of spectroscopy data and AEM results, with the following qualification. The differences between the measured and modelled values show more variance at the highest concentration range of about 2.7-3.2 M salt. 

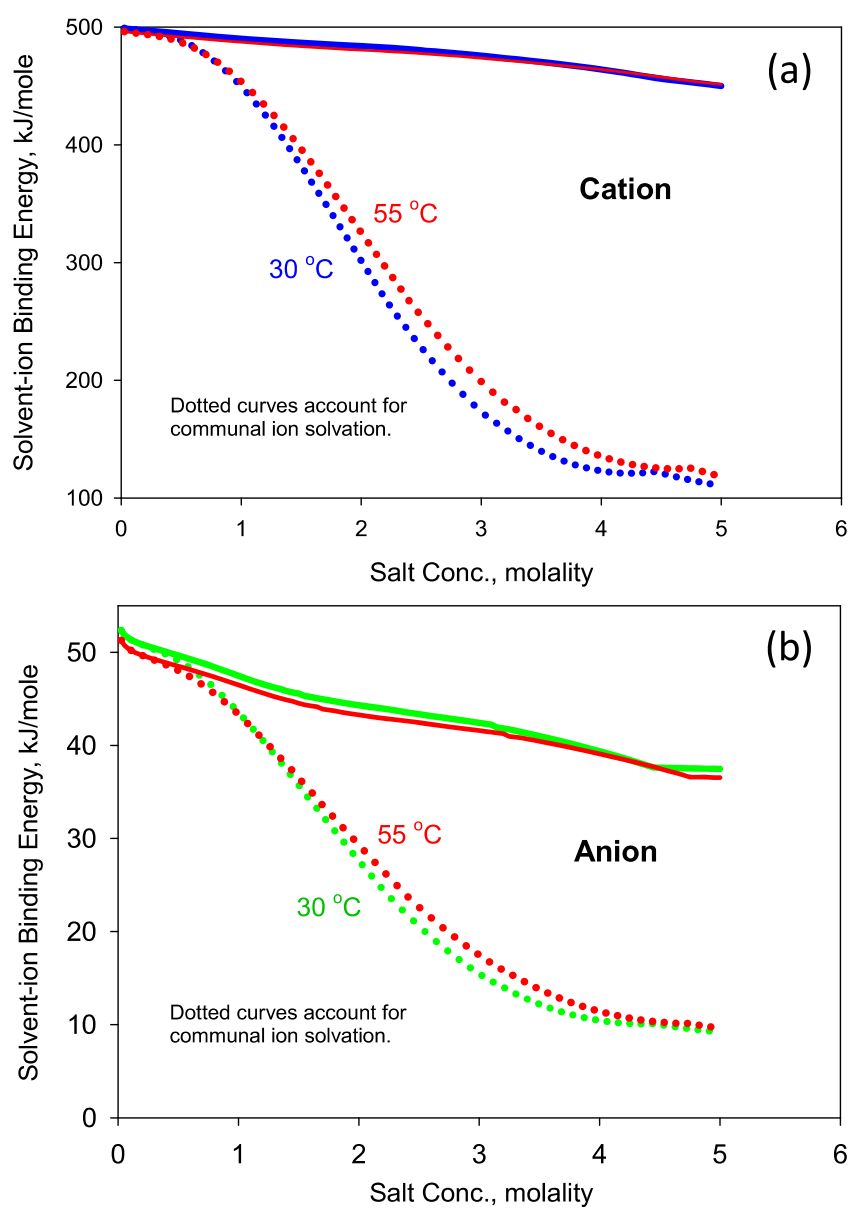

Figure 15. Average solvent-ion binding energies for $\mathrm{PC}^{-\mathrm{LiPF}_{6}}$ at $30^{\circ} \mathrm{C}$ and $55{ }^{\circ} \mathrm{C}$, as adjusted through communal ion solvation, for cations (a) and anions (b).

Perhaps one reason for this is how the AEM is assigning the solvation number cut-off, which does not assume solely wholenumber values for cation and anion solvation numbers. Another aspect is how AEM is interpreting communal ion solvation and solvation of ion pairs and triple ions, which become more prevalent at the higher salt concentrations. Hence, the AEM might be slightly conservative in predictions of ion solvation numbers at the higher concentrations for this electrolyte, which will in turn yield a modestly greater extent of solvent availability.

Solvation numbers collectively contribute to the colligative decrease of solvent activity: these numbers were calculated using a thermodynamic method adapted from Stokes and Robinson. ${ }^{62} \mathrm{Li}^{+}$ ion solvation numbers (Fig. 13b) are much higher than those of the $\mathrm{PF}_{6}{ }^{-}$ion because of the electrostatic attraction created through the strong dipole centred at the carbonyl oxygen of each PC molecule. Solvation numbers decrease with increasing salt contents due to competition for solvators by the increasing $\mathrm{Li}^{+}$ion population, in agreement with the vibrational spectroscopy data (Fig. 8). The ion solvation numbers decrease with increasing temperature. Higher temperature also increases solvent activity, i.e., the proportion of free $\mathrm{PC}$ available for interfacial reactions is higher at $55^{\circ} \mathrm{C}$ than at $30{ }^{\circ} \mathrm{C}$, which would increase the rate of parasitic reactions and affect long-term cell performance.

Solvent-ion binding energies determined by AEM are displayed in Figs. 14 and 15, wherein temperatures of 30 and $55{ }^{\circ} \mathrm{C}$ are considered. Figure 14 shows outcomes where at higher salt levels the solvent population provides shared solvator response toward ions (particularly cations), giving average effective binding energies per ion that remain relatively high, yet are spread over a network of solvent species. Values for $\mathrm{Li}^{+}$ion solvation are about an order of
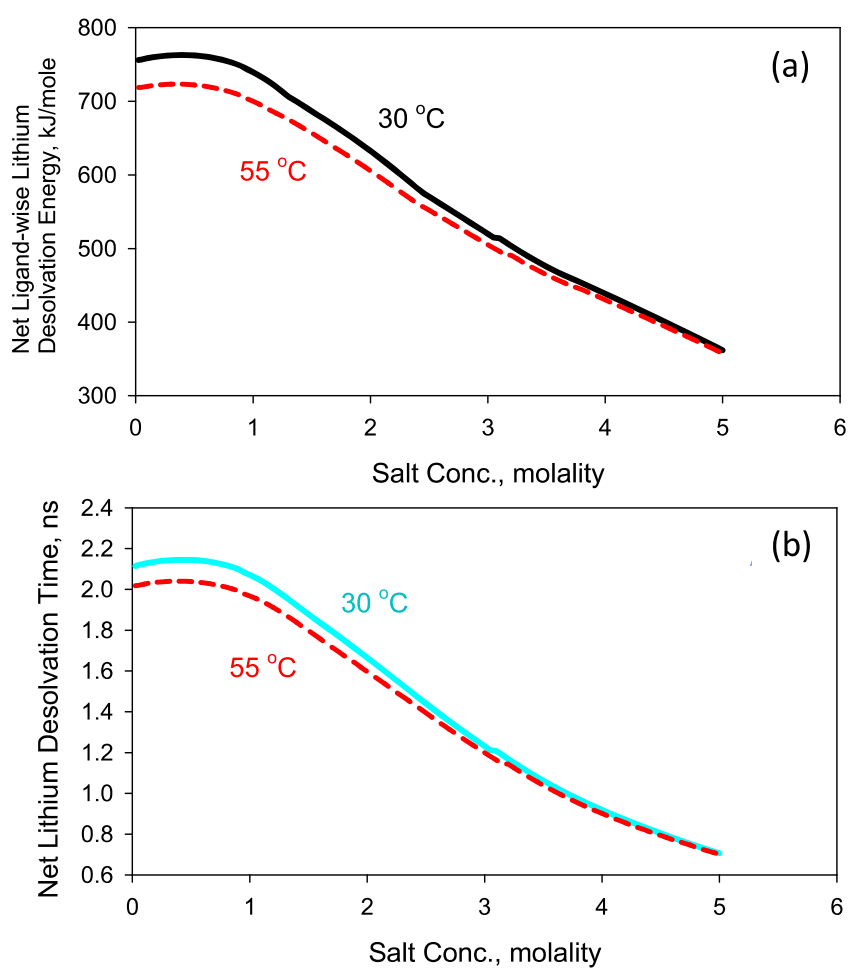

Figure 16. Net solvent- $\mathrm{Li}^{+}$desolvation energies (a) and desolvation times (b) for $\mathrm{PC}-\mathrm{LiPF}_{6}$ at $30{ }^{\circ} \mathrm{C}$ and $55^{\circ} \mathrm{C}$, as summed over all associative ligands.

magnitude larger than those for the $\mathrm{PF}_{6}{ }^{-}$ion due to the strong negative dipole created by the carbonyl oxygen and neighbouring oxygens in PC molecules, which create a correspondingly strong electrostatic attraction with cationic species. Conditions at $55{ }^{\circ} \mathrm{C}$ produce lower solvent-ion binding energies due to lower solvation numbers that exist at thermodynamic equilibrium under that condition. Two subtle inflections are noted in Fig. 14a that correspond to changes in PC solvation structures around the $\mathrm{Li}^{+}$ions: the inflection at high salt concentrations occurs in response to increased density and molecular packing at the approach of salt saturation.

Average solvent-ion binding energies, adjusted for communal ion solvation, at 30 and $55^{\circ} \mathrm{C}$ are given in Fig. 15. The solid and dotted lines show solvation energies in the absence and presence of communal solvation. According to, ${ }^{33}$ "Communal solvation describes the probability of a solvent molecule being shared as a solvator between ions. That is, under some conditions it is possible for a solvent molecule to have simultaneous participation in solvating two or more ions in close proximity. Such sharing would be more prevalent at higher salt concentrations." It is observed that ion-solvation binding energies rapidly drop when they are adjusted by normalizing per communal solvation to account for the unique per ion, per solvent basis. The resultant basis helps to explain the significantly reduced interfacial energy requirements observed for cells cycling with this electrolyte having substantially increased $(\gg 1 \mathrm{M})$ salt content. The PC- $\mathrm{Li}^{+}$solvation energy (Fig. 15a) for the 3.2 $\mathrm{M} \mathrm{LiPF}_{6}$ electrolyte is significantly lower than that of $1.2 \mathrm{M}$ $\mathrm{LiPF}_{6}$ electrolyte, which makes $\mathrm{Li}^{+}$desolvation much easier and solvent co-intercalation far less likely for the former composition. The $\mathrm{PC}-\mathrm{PF}_{6}{ }^{-}$solvation energy also decreases with increasing salt concentrations (Fig. 15b); the values are much lower than those for $\mathrm{Li}^{+}$ion, making it easier for the $\mathrm{PF}_{6}{ }^{-}$ion to desolvate and form decomposition products in the battery electrodes. Regarding the role of temperature, the impact of adjusting for communal ion solvation is less at $55^{\circ} \mathrm{C}$ than $30^{\circ} \mathrm{C}$ simply due to the lesser extent of total ion solvation present at the higher temperature.

Net solvent $-\mathrm{Li}^{+}$desolvation energies and desolvation times for PC-LiPF 6 electrolytes at 30 and $55{ }^{\circ} \mathrm{C}$ are shown in Figs. 16a 


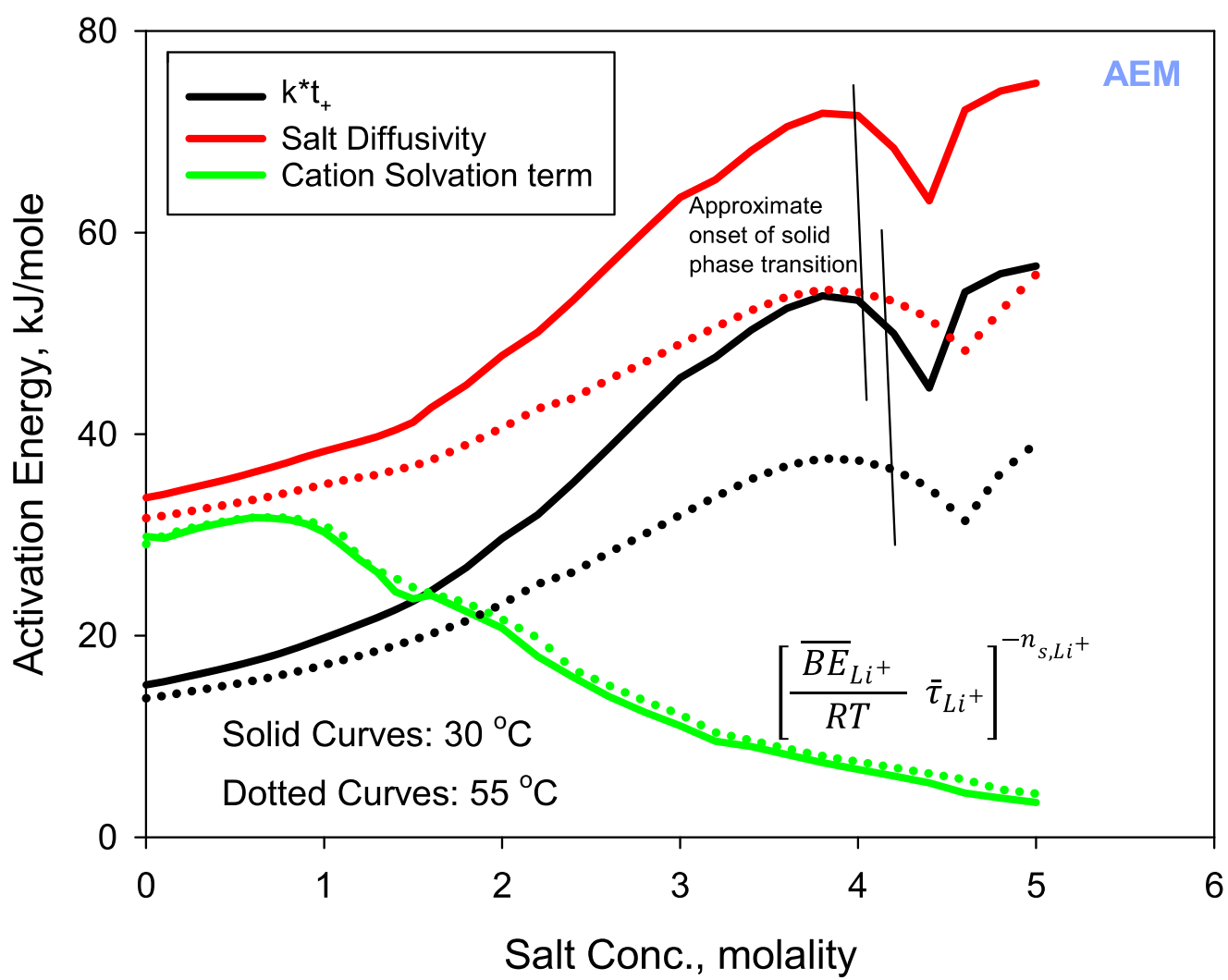

Figure 17. Activation energies $\left(\mathrm{E}_{\mathrm{a}}\right)$ for three key properties of $\mathrm{PC}-\mathrm{LiPF}_{6}$ at $30^{\circ} \mathrm{C}$ (solid) and $55^{\circ} \mathrm{C}$ (dotted): the product of conductivity and lithium transference number $\left(\mathrm{k}^{*} \mathrm{t}_{+}\right)$, salt diffusivity, and a term (see inset) that combines lithium solvation quantities.

and $16 \mathrm{~b}$, respectively. Shown values are summed over all associative ligands, here defined by cation solvation numbers. These quantities are determined through AEM by successive removal of solvators from lithium ions. Values drop by at least a third at 3 molal salt and beyond, representing lowered energetic and kinetic requirements for desolvation of $\mathrm{Li}^{+}$ion reaching an electrode surface. Values shown in Fig. 16 serve as the baseline for the chosen electrolyte; other surface and SEI effects, unique to each electrode, should be considered in tandem with this baseline to determine the complete impedance to $\mathrm{Li}^{+}$desolvation prior to insertion. Convergence of the $30{ }^{\circ} \mathrm{C}$ and $55{ }^{\circ} \mathrm{C}$ curves at higher salt concentrations indicates that $\mathrm{Li}^{+}$ion solvation outcomes exceed those of thermal consequences at high ionic populations.

Activation energy $\left(\mathrm{E}_{\mathrm{a}}\right)$ values of various electrolyte properties can be obtained by applying the Arrhenius equation at distinct conditions of salt concentration and temperature. Figure 17 shows $\mathrm{E}_{\mathrm{a}}$ for three of the metrics provided by AEM for PC-LiPF 6 at $30{ }^{\circ} \mathrm{C}$ and $55{ }^{\circ} \mathrm{C}$ : the product of conductivity and lithium transference number $\left(\mathrm{k}^{*} \mathrm{t}_{+}\right)$, salt diffusivity $\left(\mathrm{D}_{\text {salt }}\right)$, and a "cation-solvation" term that combines the foremost $\mathrm{Li}^{+}$solvation quantities. In the latter, $\mathrm{BE}$ is the average solvent-to-lithium binding energy, $\tau$ is the average solvent residence time around a lithium ion, and $n_{s}$ is the solvation number. The activation energy analysis indicates that within an operating $\mathrm{Li}$-ion cell, $\mathrm{Li}^{+}$transport will become more difficult at higher salt concentrations, while lithium desolvation will improve. Added to this is the consequence of concentration polarization that will become more pronounced at higher cell cycling rates, causing salt enrichment at one side of the cell, while salt depletion will occur at the other side. ${ }^{63}$ This consequence causes a wider disparity of activation energies for $\mathrm{Li}^{+}$transport, creating a greater state of disequilibrium within a cell. However, $\mathrm{E}_{\mathrm{a}}$ for transport quantities decrease at the higher temperature indicating that cell disequilibrium would be partially mitigated by operation at higher temperatures where there is improved, more consistent transport properties.
Results for the cation solvation term confirm that the $\mathrm{Li}^{+}$desolvation process has lower activation energies at high salt concentrations, which makes the process more tenable. Furthermore, the activation energy analysis appears to be a reliable method to confirm emergence of solid-phase transitions in the electrolyte, showing correct trends in Fig. 17 in terms of the onset of solid phase transition being pushed to higher salt concentrations at the higher temperature.

This effect of concentration polarization may partially explain the pulse-impedance behaviour displayed in Fig. 3. During the discharge pulse, salt enrichment would occur within the graphite anode, while salt depletion would occur within the oxide cathode: higher the current pulse, greater the salt enrichment or depletion. For the $3.2 \mathrm{M}$ $\mathrm{LiPF}_{6}$ cell, anode salt concentration increases beyond $3.2 \mathrm{M}$ during the current pulse resulting in lower $\mathrm{Li}^{+}$conductivity and higher impedance. Conversely, at the cathode salt concentration decreases below $3.2 \mathrm{M}$ resulting in higher $\mathrm{Li}^{+}$conductivity and lower impedance. During the charge pulse, salt enrichment in the oxide cathode would decrease $\mathrm{Li}^{+}$conductivity and increase impedance; salt depletion in the graphite anode would increase $\mathrm{Li}^{+}$conductivity and decrease impedance. Furthermore, the salt contents could exceed solubility limits in the enrichment zone, with detrimental effects on cell performance. We acknowledge that this explanation is simplistic because it does not account for $\mathrm{Li}^{+}$migration/diffusion through the interphases on the graphite and oxide particles. Transport into (and out of) the oxide is further complicated by the presence of nonlayered phases on the particle surfaces ${ }^{64}$ and by lithium-plating that occurs on graphite particles at high pulse currents. ${ }^{65}$

\section{Conclusions}

We examined the electrochemical and physicochemical characteristics of $\mathrm{PC}$ solutions containing various amounts of $\mathrm{LiPF}_{6}$ salt. The highlights from our studies are as listed below: 
- Graphite electrodes can be cycled in PC solutions when the dissolved $\mathrm{LiPF}_{6}$ salt concentration exceeds $2.4 \mathrm{M}$; graphite particles harvested from cells with $3.2 \mathrm{M} \mathrm{LiPF}_{6}$ do not show exfoliation.

- NCA//Graphite cells can be cycled in 3.2 $\mathrm{M} \mathrm{LiPF}_{6} / \mathrm{PC}$ electrolyte. Data from 3-electrode cells show that both the oxide and graphite electrode impedances are higher than those in cells with the Gen2 electrolyte. When cycled at $55{ }^{\circ} \mathrm{C}$, the $3.2 \mathrm{M} \mathrm{LiPF}_{6} / \mathrm{PC}$ cells have lower initial capacities than Gen2 electrolyte cells; however, capacity fade rate is similar for both types of cells.

- Graphite cyclability in HCEs does not result from "enhanced" SEIs; rather, it's related to other properties, such as $\mathrm{Li}^{+}$solvation/ desolvation characteristics.

- Vibrational spectroscopies (IR, Raman) reveal major changes in the bulk electrolyte structure for $>2.4 \mathrm{M} \mathrm{LiPF}_{6} / \mathrm{PC}$, which include the following: (i) $\mathrm{SN}_{\mathrm{Li}-\mathrm{PC}}$ starts to linearly decrease with salt concentration, (ii) $\left[P F_{6}^{-}\right]_{\text {free }}>[P C]_{\text {free }}$, i.e., there are more free anions than free solvents in the bulk electrolyte, and (iii) the $[P C]_{\text {free }}$ does not reach zero, even at $3.2 \mathrm{M} \mathrm{LiPF}_{6}$.

- Computational investigations (DFT, AIMD) show that (i) the amounts of anions in the solvation shell increase with salt concentration, (ii) desolvation becomes easier when anions are present in the solvation shell.

- AEM results show that $\mathrm{Li}^{+}$ion transport within an operating cell will become impeded at higher salt concentrations due largely to viscosity effects, while lithium desolvation becomes easier. Concentration polarization will be more pronounced for the HCEs, especially at higher cycling rates, causing salt enrichment at one electrode and salt depletion at the other. The amount of free PC available for redox reactions at the electrode decreases significantly at higher salt contents, which explains the low organic contents in the electrode surface films. The highly inorganic interphases formed on the oxide and graphite particle surfaces are likely responsible for the higher interfacial impedance observed for the $3.2 \mathrm{M} \mathrm{LiPF}_{6} / \mathrm{PC}$ cell compared to that of a Gen 2 electrolyte cell.

\section{Acknowledgments}

GA and PJ are grateful for the financial support from the Swedish Energy Agency by the projects within "Batterifondsprogrammet": "Next Generation Batteries" (\#37671-1) and "Highly Concentrated Electrolytes" (\#39909-1). The continuous support to PJ from several of Chalmers Areas of Advance: Materials Science, Energy, and Transport, is also gratefully acknowledged. GA and PJ are also grateful for the computational resources provided by the Swedish National Infrastructure for Computing (SNIC) at Chalmers Centre for Computational Science and Engineering (C3SE). GC and DPA gratefully acknowledge support from the Vehicle Technologies Office, Energy Efficiency and Renewable Energy, U.S. Department of Energy (DOE). Argonne National Laboratory, a U. S. DOE Office of Science laboratory, is operated under Contract No. DE-AC0206CH11357. Idaho National Laboratory operates under DOE-ID contract No. DE-AC07-05ID14517. The U. S. Government retains for itself, and others acting on its behalf, a paid-up nonexclusive, irrevocable worldwide license in said article to reproduce, prepare derivative works, distribute copies to the public, and perform publicly and display publicly, by or on behalf of the Government.

\section{ORCID}

Gustav Åvall (iD https://orcid.org/0000-0002-1458-0515

Kevin L. Gering (iD https://orcid.org/0000-0002-2821-4057

Patrik Johansson (iD https://orcid.org/0000-0002-9907-117X

Daniel P. Abraham (D) https://orcid.org/0000-0003-0402-9620

\section{References}

1. K. Xu, Chem. Rev., 104, 4303 (2004).

2. J. O. Besenhard and H. P. Fritz, Angew. Chemie Int. Ed. English, 22, 950 (1983)

3. M. Arakawa and J.-I. Yamaki, J. Electroanal. Chem., 219, 273 (1987).
4. J. O. Besenhard and H. P. Fritz, J. Electroanal. Chem. Interfacial Electrochem., 53, 329 (1974)

5. G. Eichinger, J. Electroanal. Chem. Interfacial Electrochem., 74, 183 (1976)

6. A. N. Dey and B. P. Sullivan, J. Electrochem. Soc., 117, 222 (1970).

7. Y. Yamada, J. Wang, S. Ko, E. Watanabe, and A. Yamada, Nat. Energy, 4, 269 (2019).

8. Y. Yamada and A. Yamada, J. Electrochem. Soc., 162, A2406 (2015).

9. O. Borodin, J. Self, K. A. Persson, C. Wang, and K. Xu, Joule, 4, 69 (2020).

10. S. K. Jeong, M. Inaba, Y. Iriyama, T. Abe, and Z. Ogumi, Electrochem. Solid-State Lett., 6, 15 (2003).

11. M. Nie, D. P. Abraham, D. M. Seo, Y. Chen, A. Bose, and B. L. Lucht, J. Phys. Chem. C, 117, 25381 (2013)

12. Y. Aoki, S. Oda, M. Oda, M. Ogawa, T. Ishihama, T. Doi, and M. Inaba, J. Electrochem. Soc., 168, 020530 (2021)

13. J. Barthel, R. Buchner, and E. Wismeth, J. Solution Chem., 29, 937 (2000).

14. Y. Kameda, Y. Umebayashi, M. Takeuchi, M. A. Wahab, S. Fukuda, S.-I. Ishiguro, M. Sasaki, Y. Amo, and T. Usuki, J. Phys. Chem. B, 111, 6104 (2007).

15. P. A. Brooksby and W. R. Fawcett, Spectrochim. Acta Part A Mol. Biomol. Spectrosc., 64, 372 (2006)

16. T. Fukushima, Y. Matsuda, H. Hashimoto, and R. Arakawa, Electrochem. SolidState Lett., 4, A127 (2001).

17. Y. Matsuda, H. Nakashima, M. Morita, and Y. Takasu, J. Electrochem. Soc., 128 2552 (1981).

18. Y. Yamada, Y. Koyama, T. Abe, and Z. Ogumi, J. Phys. Chem. C, 113, 8948 (2009)

19. H. Tsunekawa, A. Narumi, M. Sano, A. Hiwara, M. Fujita, and H. Yokoyama J. Phys. Chem. B, 107, 10962 (2003).

20. S. Hwang, D.-H. Kim, J. H. Shin, J. E. Jang, K. H. Ahn, C. Lee, and H. Lee, J. Phys. Chem. C, 122, 19438 (2018)

21. M. Morita, Y. Asai, N. Yoshimoto, and Ishikawa, J. Chem. Soc. Faraday Trans., 94, 3451 (1998).

22. J. L. Allen, O. Borodin, D. M. Seo, and W. A. Henderson, J. Power Sources, 267, 821 (2014)

23. D. M. Seo, S. Reininger, M. Kutcher, K. Redmond, W. B. Euler, and B. L. Lucht, J. Phys. Chem. C, 119, 14038 (2015).

24. N. Chapman, O. Borodin, T. Yoon, C. C. Nguyen, and B. L. Lucht, J. Phys. Chem C, 121, 2135 (2017).

25. M. Takeuchi, Y. Kameda, Y. Umebayashi, S. Ogawa, T. Sonoda, S.-I. Ishiguro, M. Fujita, and M. Sano, J. Mol. Liq., 148, 99 (2009).

26. J. Self, K. D. Fong, and K. A. Persson, ACS Energy Lett., 4, 2843 (2019).

27. Y. Ikezawa and T. Ariga, Electrochim. Acta, 52, 2710 (2007).

28. L. Doucey, M. Revault, A. Lautié, A. Chaussé, and R. Messina, Electrochim. Acta 44, 2371 (1999).

29. D. Battisti, G. A. Nazri, B. Klassen, and R. Aroca, J. Phys. Chem., 97, 5826 (1993)

30. G. J. Janz, J. Ambrose, J. W. Coutts, and J. R. Downey, Spectrochim. Acta Part A Mol. Spectrosc., 35, 175 (1979)

31. R. A. Pethrick and A. D. Wilson, Spectrochim. Acta Part A Mol. Spectrosc., 30, 1073 (1974).

32. H. L. Yeager, J. D. Fedyk, and R. J. Parker, J. Phys. Chem., 77, 2407 (1973)

33. K. L. Gering, Electrochim. Acta, 51, 3125 (2006).

34. K. L. Gering, Electrochim. Acta, 225, 175 (2017).

35. D. P. Abraham, D. W. Dees, J. Christophersen, C. Ho, and A. N. Jansen, Int. J. Energy Res., 34, 190 (2010)

36. D. P. Abraham, M. M. Furczon, S.-H. Kang, D. W. Dees, and A. N. Jansen, J. Power Sources, 180, 612 (2008)

37. J. Jaumot, A. de Juan, and R. Tauler, Chemom. Intell. Lab. Syst., 140, 1 (2015)

38. K. Kondo, M. Sano, A. Hiwara, T. Omi, M. Fujita, A. Kuwae, M. Iida, K. Mogi, and H. Yokoyama, J. Phys. Chem. B, 104, 5040 (2000).

39. Y. Zhao and D. G. Truhlar, Theor. Chem. Acc., 120, 215 (2008)

40. J. B. Foresman and Æ. Firsch, Exploring Chemistry with Electronic Structure Methods (Gaussian Inc., Wallingford, CT) 3rd ed. (2015).

41. M. J. Frisch et al., Gaussian 16, Revision A.03. Gaussian, Inc., Wallingford CT (2016).

42. E. Cancès, B. Mennucci, and J. Tomasi, J. Chem. Phys., 107, 3032 (1997).

43. J. Tomasi, B. Mennucci, and R. Cammi, Chem. Rev., 105, 2999 (2005)

44. See (http//www.cpmd.org/) for CPMD, Copyright IBM Corp 1990-2019, Copyrigh MPI für Festkörperforschung Stuttgart 1997-2001.

45. M. Parrinello and R. Car, Phys. Rev. Lett., 55, 2471 (1985).

46. C. Hartwigsen, S. Goedecker, and J. Hutter, Phys. Rev. B, 58, 3641 (1998)

47. S. Goedecker, M. Teter, and J. Hutter, Phys. Rev. B, 54, 1703 (1996).

48. M. Krack, Theor. Chem. Acc., 114, 145 (2005).

49. R. Andersson, F. Årén, A. A. Franco, and P. Johansson, arXiv:2102.01768 [physics chem-ph] (2021).

50. E. R. Logan, E. M. Tonita, K. L. Gering, and J. R. Dahn, J. Electrochem. Soc., 165 , A3350 (2018).

51. A. Dave, K. L. Gering, J. M. Mitchell, J. Whitacre, and V. Viswanathan, J. Electrochem. Soc., 167, 013514 (2020).

52. K. Xu, J. Electrochem. Soc., 156, A751 (2009).

53. M. Forsyth, H. Yoon, F. Chen, H. Zhu, D. R. MacFarlane, M. Armand, and P. C. Howlett, J. Phys. Chem. C, 120, 4276 (2016).

54. F. Chen and M. Forsyth, Phys. Chem. Chem. Phys., 18, 19336 (2016).

55. J. Wahlers, K. D. Fulfer, D. P. Harding, D. G. Kuroda, R. Kumar, and R. Jorn J. Phys. Chem. C, 120, 17949 (2016)

56. G. Åvall and P. Johansson, J. Chem. Phys., 152, 234104 (2020).

57. R. Andersson, F. Årén, A. A. Franco, and P. Johansson, J. Electrochem. Soc., 167, 140537 (2020) 
58. K. D. Fulfer and D. G. Kuroda, J. Phys. Chem. C, 120, 24011 (2016).

59. E. Flores, G. Åvall, S. Jeschke, and P. Johansson, Electrochim. Acta, 233, 134 (2017).

60. Y. Yamada, K. Furuawa, K. Sodeyama, K. Kikuchi, M. Yaegashi, Y. Tateyama, and A. Yamada, J. Am. Chem. Soc., 136, 5039 (2014).

61. Y. Yamada, M. Yaegashi, T. Abe, and A. Yamada, Chem. Commun., 49, 11194 (2013)
62. R. H. Stokes and R. A. Robinson, J. Sol. Chem., 2, 173 (1973).

63. D. Dees, E. Gunen, D. Abraham, A. Jansen, and J. Prakash, J. Electrochem. Soc., 155, A603 (2008)

64. D. P. Abraham, R. D. Twesten, M. Balasubramanian, I. Petrov, J. McBreen, and K. Amine, Electrochem. Commun., 44, 620 (2002).

65. M.-T. F. Rodrigues, I. A. Shkrob, A. M. Colclasure, and D. P. Abraham, J. Electrochem. Soc., 167, 130508 (2020). 